\title{
Linking hydraulic traits to tropical forest function in a size-structured and trait-driven model (TFS v.1-Hydro)
}

\author{
Bradley O. Christoffersen ${ }^{1,2}$, Manuel Gloor ${ }^{3}$, Sophie Fauset ${ }^{3}$, Nikolaos M. Fyllas ${ }^{4}$, David R. Galbraith ${ }^{3}$, Timothy \\ R. Baker ${ }^{3}$, Bart Kruijt ${ }^{5}$, Lucy Rowland ${ }^{2,6}$, Rosie A. Fisher ${ }^{7}$, Oliver J. Binks ${ }^{2}$, Sanna Sevanto ${ }^{1}$, Chonggang Xu ${ }^{1}$, \\ Steven Jansen $^{8}$, Brendan Choat ${ }^{9}$, Maurizio Mencuccini ${ }^{2,10}$, Nate G. McDowell ${ }^{1}$, and Patrick Meir ${ }^{2,11}$ \\ ${ }^{1}$ Earth and Environmental Sciences, Los Alamos National Laboratory, Los Alamos, New Mexico, USA \\ ${ }^{2}$ School of GeoSciences, University of Edinburgh, Edinburgh, UK \\ ${ }^{3}$ School of Geography, University of Leeds, Leeds, UK \\ ${ }^{4}$ Department of Ecology and Systematics, University of Athens, Athens, Greece \\ ${ }^{5}$ Wageningen Environmental Research (ALTERRA), Wageningen, the Netherlands \\ ${ }^{6}$ Geography, College of Life and Environmental Sciences, University of Exeter, Exeter, UK \\ ${ }^{7}$ Climate \& Global Dynamics, National Center for Atmospheric Research, Boulder, Colorado, USA \\ ${ }^{8}$ Institute of Systematic Botany and Ecology, Ulm University, Ulm, Germany \\ ${ }^{9}$ Hawkesbury Institute for the Environment, Western Sydney University, Richmond, New South Wales 2753, Australia \\ ${ }^{10}$ ICREA at CREAF, Cerdanyola del Vallès, Barcelona 08193, Spain \\ ${ }^{11}$ Research School of Biology, Australian National University, Canberra, Australia
}

Correspondence to: Bradley O. Christoffersen (bradley@lanl.gov)

Received: 23 May 2016 - Published in Geosci. Model Dev. Discuss.: 14 June 2016

Revised: 7 October 2016 - Accepted: 1 November 2016 - Published: 24 November 2016

\begin{abstract}
Forest ecosystem models based on heuristic water stress functions poorly predict tropical forest response to drought partly because they do not capture the diversity of hydraulic traits (including variation in tree size) observed in tropical forests. We developed a continuous porous media approach to modeling plant hydraulics in which all parameters of the constitutive equations are biologically interpretable and measurable plant hydraulic traits (e.g., turgor loss point $\pi_{\text {tlp }}$, bulk elastic modulus $\varepsilon$, hydraulic capacitance $C_{\mathrm{ft}}$, xylem hydraulic conductivity $k_{\mathrm{s} \text {, max }}$, water potential at $50 \%$ loss of conductivity for both xylem $\left(P_{50, \mathrm{x}}\right)$ and stomata $\left(P_{50, \mathrm{gs}}\right)$, and the leaf: sapwood area ratio $A_{1}: A_{\mathrm{S}}$ ). We embedded this plant hydraulics model within a trait forest simulator (TFS) that models light environments of individual trees and their upper boundary conditions (transpiration), as well as providing a means for parameterizing variation in hydraulic traits among individuals. We synthesized literature and existing databases to parameterize all hydraulic traits as a function of stem and leaf traits, including wood density (WD), leaf mass per area (LMA), and photosynthetic capacity $\left(A_{\max }\right)$, and evaluated the coupled model (called TFS v.1-Hydro) pre-
\end{abstract}

dictions, against observed diurnal and seasonal variability in stem and leaf water potential as well as stand-scaled sap flux.

Our hydraulic trait synthesis revealed coordination among leaf and xylem hydraulic traits and statistically significant relationships of most hydraulic traits with more easily measured plant traits. Using the most informative empirical traittrait relationships derived from this synthesis, TFS v.1-Hydro successfully captured individual variation in leaf and stem water potential due to increasing tree size and light environment, with model representation of hydraulic architecture and plant traits exerting primary and secondary controls, respectively, on the fidelity of model predictions. The plant hydraulics model made substantial improvements to simulations of total ecosystem transpiration. Remaining uncertainties and limitations of the trait paradigm for plant hydraulics modeling are highlighted. 


\section{Introduction}

Tropical forests harbor great biodiversity (Myers et al., 2000; ter Steege et al., 2013) and play an important role in regulating regional and global climate (Gash and Nobre, 1997; Silva Dias et al., 2002). However, climate change is inducing changes to the hydrological regime of tropical forests (Feng et al., 2013; Fu et al., 2013; Gloor et al., 2013), with some consensus for a projected increase in drought frequency over the coming century via an intensification of precipitation seasonality (Joetzjer et al., 2013; Boisier et al., 2015), an increase in El Niño events (Cai et al., 2014), and chronically rising atmospheric moisture demand (McDowell and Allen, 2015), even as the directional change of total precipitation remains highly uncertain (Solomon, 2007). Therefore, because of their intrinsic value and strong coupling to the regional and global climate system, it is of paramount importance to have a predictive capability of tropical forest response to changes in water availability (Kumagai and Porporato, 2012; Oliveira et al., 2014; Meir et al., 2015).

Evaluations of many coarse-scale forest ecosystem models in the species-rich tropics indicate a poor predictive ability of these models to simulate tropical forest response to drought (Galbraith et al., 2010; Powell et al., 2013; Joetzjer et al., 2014; Rowland et al., 2015b). While most of these models treat soil water fluxes mechanistically, soil-root and internal plant water fluxes are not mechanistically modeled; consequently, dynamic changes in plant moisture stress in these models are driven by changes in soil water status alone (discussed in Feddes et al., 1978; Egea et al., 2011; Xu et al., 2013; Verhoef and Egea, 2014). Additionally, water stress in many models includes relatively few plant functional type (PFT)-dependent parameters; thus, models are largely ignorant of plant traits that may control response to moisture. In contrast, a mechanistic treatment of plant hydraulics allows water stress to be driven by changes in leaf water status (Sperry and Love, 2015). Coupled with site-specific parameterization, the plant hydraulics approach enables high-fidelity simulation of tropical forest response to moisture (Fisher et al., 2006, 2007).

While a range of approaches exist for modeling plant hydraulics at fine scales (i.e., individual trees), all involve an extension of Darcy's law (Darcy, 1856) from the soil domain to include plants as well. Darcy's law states that water flux anywhere in the soil-plant continuum is proportional to the product of soil or plant hydraulic conductivity and a gradient in water potential. In order for these models to capture drought response, hydraulic conductivity within the soil-plant continuum must dynamically respond to changes in moisture. Three main approaches are distinguished in terms of how they represent the impact of declines in water potential on tissue water content and xylem hydraulic conductivity. A first class of models is the simplest and simulates moisture sensitivity of soil-root conductance but not xylem hydraulic conductance (Jarvis et al., 1981; Williams et al., 1996; Ogée et al., 2003; Alton et al., 2009; Bonan et al., 2014). This approach has proven useful for modeling the effects experimental drought in tropical forests (Williams et al., 1998; Fisher et al., 2006, 2007), but it remains unclear whether this approach misattributes drought effects occurring within trees to the soil; therefore, a second class of models implements variable xylem conductivity with xylem water potential (Williams et al., 2001; Hickler et al., 2006; Domec et al., 2012; Duursma and Medlyn, 2012; Xu et al., 2016). To simplify computational load, these two approaches do not explicitly track dynamic changes in the volume of plant water storage. Instead, a constant ratio of change in stored water per unit change in water potential, or stem hydraulic capacitance, is assumed, which may overestimate the buffering capacity of tree-stored water under extreme drought conditions when small relative declines in stored water induce very large declines in water potential. An additional consequence of the design of these models is the inability to represent the bidirectional flow of water at the root-soil interface. Reverse flow of water from roots into soil is an important process in root hydraulic distribution (Oliveira et al., 2005), and may also mediate time to desiccation under drought (North and Nobel, 1997).

A convenient way to address these issues is in a third class of models (hereafter the "continuous porous media approach"), which simply extend the modeled mass balance of water from the soil domain into the plant by relating simulated changes in water content to water potential (and vice versa) everywhere within the plant-soil continuum (Edwards et al., 1986; Arbogast et al., 1993; Sperry et al., 1998; Kumagai, 2001; Bohrer et al., 2005; Mackay et al., 2015; Mirfenderesgi et al., 2016). While more computationally complex, the continuous porous media approach offers two main advantages in addition to addressing the issue of plant water storage and bidirectional root flow. First, the coupled plantsoil system is represented by a single mass balance equation, such that root water uptake or loss simply emerges from the solution of this equation, and does not need to be ascribed post hoc as is the case in the first two approaches. Second, this approach relies on an explicit description of the relationship between water content and water potential in plant xylem (the pressure-volume, or PV curve), analogous to the water retention curves used in soil physics. As we will show, there is a wealth of information on PV hydraulic traits for leaves and, to a lesser degree, stems in tropical forests. Implementing PV curves in the model greatly increases the scope of data with which the model can be parameterized. In this paper, we develop a continuous porous media approach intended for application at specific sites in the tropics to explore dynamics of water fluxes from hourly to seasonal timescales and at spatial scales ranging from individual trees to the stand-level scale. This intermediate-scale approach is a model test bed meant to inform implementations of plant hydraulics in coarse-scale forest ecosystem models.

Model parameterization leads us to the challenge of how to represent variation in plant hydraulic traits governing mois- 
ture sensitivity and water transport capacity. It has long been recognized that the functional trait diversity of tropical forests mirrors their large species diversity (Corner, 1949; Hallé et al., 1978; Leigh, 1999), and diversity in plant hydraulic traits such as the water potential at turgor loss $\left(\pi_{\mathrm{tlp}}\right)$ and at $50 \%$ loss of conductivity $\left(P_{50}\right)$, xylem-specific hydraulic conductivity $\left(k_{\mathrm{s}, \max }\right)$, and the leaf-to-sapwood area ratio $\left(A_{1}: A_{\mathrm{S}}\right)$ is no exception (Borchert, 1994; Tobin et al., 1999; Lopez et al., 2005; Meinzer et al., 2008a; Zhu et al., 2013). Interspecific variation in these traits is thought to mediate species differences in survival in both natural and experimentally induced droughts (Nakagawa et al., 2000; Engelbrecht and Kursar, 2003; Kursar et al., 2009; Moser et al., 2014; Meir et al., 2015). Differential drought sensitivity, in turn, is known to explicitly link to species distributions (Choat et al., 2007; Engelbrecht et al., 2007; Baltzer et al., 2008; Condit et al., 2013). Mechanistic plant hydraulics also allows for diversity in tree height, already included in sizestructured forest ecosystem models, to act as a hydraulic trait because it influences the path length over which water must traverse to reach the canopy. Larger trees often demonstrate significantly higher vulnerability to drought (Nakagawa et al., 2000; Nepstad et al., 2007; da Costa et al., 2010; Rowland et al., 2015a), a trend demonstrated to be pantropical in scope (Phillips et al., 2010; Bennett et al., 2015). Such a trend highlights that the increasing hydraulic path length associated with tall trees (and perhaps increased radiation loads) is an equally important determinant of drought sensitivity (McDowell and Allen, 2015).

The implication for ecosystem models is that underrepresentation of diversity in functional traits and tree size in tropical forests is undermining efforts to make accurate projections of tropical forest response to climate. Model parameterization of hydraulic trait diversity should thus provide much-needed model capability to represent a diversity of responses to changes in moisture availability, laying the groundwork for representing trait-mediated differences in survival and subsequent shifts in forest trait composition. Shifts in trait composition are already occurring in some tropical forests (e.g., Enquist and Enquist, 2011; van der Sande et al., 2016), and such shifts (or the diversity of traits alone) have been shown to buffer ecosystems in the face of environmental change, and in some cases, are the difference between predicted complete loss of forest and forest persistence (Fauset et al., 2012; Levine et al., 2016; Sakschewski et al., 2016).

Because a complete representation of trait diversity in models is neither tractable nor desired, the challenge is to identify and represent the dominant dimensions of trait variation within our plant hydraulics model. To date, syntheses of hydraulic traits have typically focused on a limited set of traits in isolation (Bartlett et al., 2012; Choat et al., 2012; Nardini et al., 2014; Anderegg, 2015); also see Mencuccini et al. (2015). In contrast, here we synthesize how a large suite of hydraulic traits represented in our model vary with better quantified dimensions of plant functional trait variation, such as the leaf (Wright et al., 2004) and stem (Chave et al., 2009) economics spectra. We make no a priori assumptions about the coordination (or lack thereof) between leaf and stem economics, given the conflicting evidence (Baraloto et al., 2010; Mendez-Alonzo et al., 2012; Reich, 2014). In addition, we assess the evidence for trade-offs and coordination among hydraulic traits, independent of leaf and stem economic traits.

In what follows, we first describe the continuous porous media hydraulics module that simulates the fast-timescale (hourly) processes of tree water flux and water potential gradients throughout the soil-plant continuum. Second, via a pantropical synthesis of hydraulic traits, we derive empirical relationships for parameterizing hydraulic trait variation in the plant hydraulics model. Third, we demonstrate the model's capability to simulate different individual-level functional responses to environmental variation (either water or light), arising from hydraulic limitations imposed by tree size or hydraulic traits. Finally, we evaluate the new model in terms of its ability to capture diurnal dynamics of water potential, individual-level variation in leaf water status, and the observed seasonal dynamics of ecosystem-level water use.

\section{Model description: plant hydraulics and host individual trait-driven forest models}

The plant hydraulics model developed here is integrated into a "host" individual tree trait-driven forest model (trait forest simulator, TFS). A TFS simulates every tree in a stand $>10 \mathrm{~cm}$ diameter at breast height (DBH) driven by plot observations of the tree size distribution, and each tree can possess a unique set of values of the four functional traits: wood density (WD), leaf mass per area (LMA), leaf nitrogen $\left(\mathrm{N}_{\mathrm{L}}\right)$, and leaf phosphorus $\left(\mathrm{P}_{\mathrm{L}}\right)$. The modification of transpiration fluxes in TFS by the plant hydraulics module can be summarized as follows (see Fig. 1): the hydraulics module passes to TFS a nondimensional multiplier (fraction of maximum conductance, $\left.\mathrm{FMC}_{\mathrm{gs}}\right)(0,1]$ for each tree, which is based on each tree's leaf water potential at the previous time step. TFS uses $\mathrm{FMC}_{\mathrm{gs}}$ within its biophysics calculations to estimate transpiration fluxes for each tree at the current time step, and the transpiration of each tree is passed back to the hydraulics model, which computes changes in water potential and water content throughout the soil-plant continuum (including root water uptake or loss) due to transpiration. The plant hydraulics module also assigns hydraulic traits based on each tree's size and pre-assigned plant functional traits. Below we describe the components of the plant hydraulics model (Sect. 2.1), and at the end of each subsection highlight the key hydraulic traits for which we seek to understand trait trade-offs and coordination via our empirical synthesis. Section 2.2 gives a description of the host TFS model. The Supplement $\mathrm{S} 1$ gives a full technical description of the hydraulics 


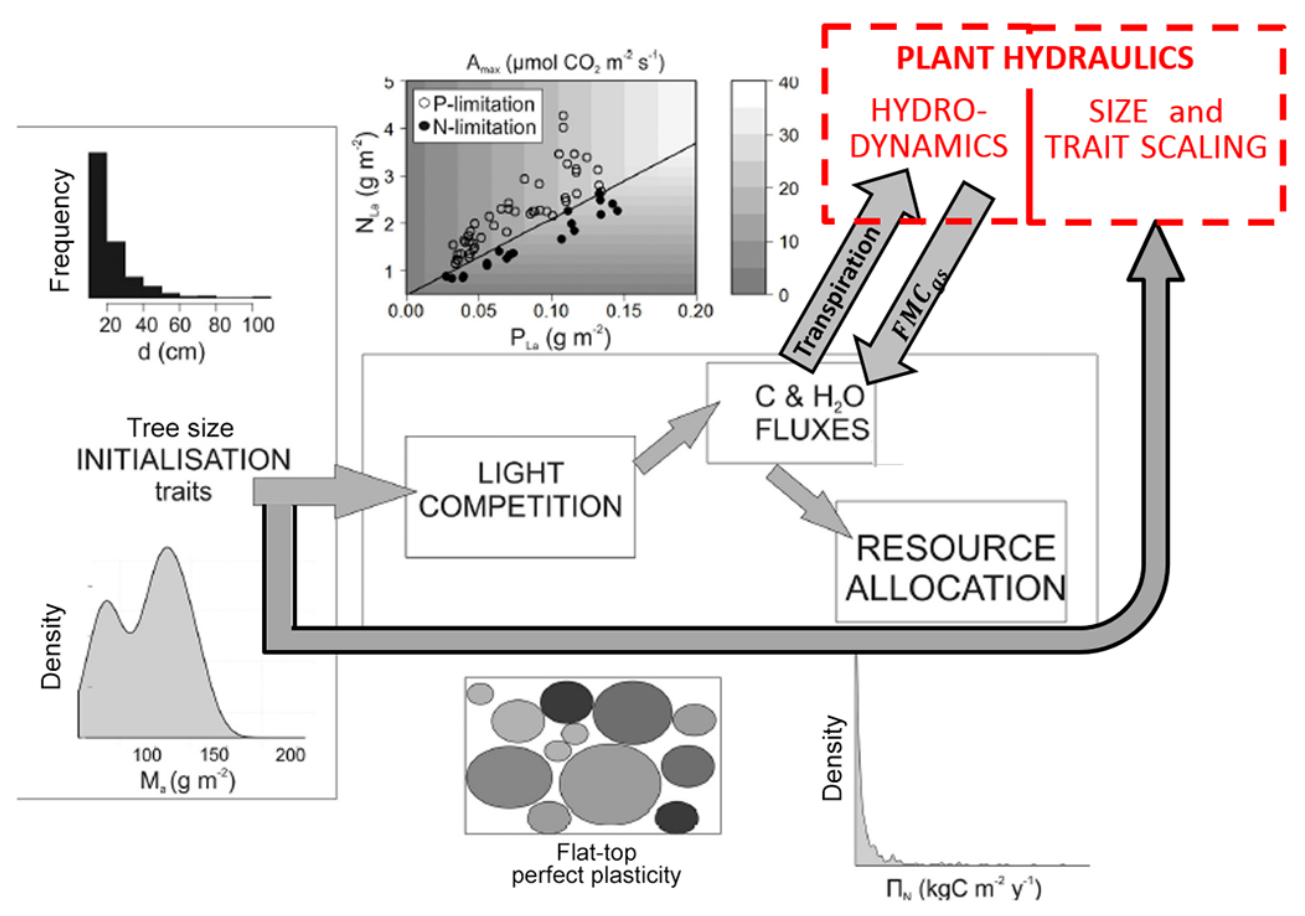

Figure 1. Overview of TFS v.1-Hydro model. Left panel: inputs are plot observations of the tree size distribution and distributions of each of four plant functional traits (WD, LMA, $\mathrm{N}_{\mathrm{L}}, \mathrm{P}_{\mathrm{L}}$ ). Middle bottom: the perfect plasticity approximation (PPA) orders trees by decreasing crown area. Middle top: TFS assigns physiological traits, such as $V_{\mathrm{c}, \max }$, to each tree based on functional traits. Middle: the PPA is used to estimate light environments of each tree, which influence fast-timescale (hourly) biophysics of crown light interception, photosynthesis, and stomatal conductance. Assimilated carbon is allocated to leaves, stems, and fine roots daily. Top right (hydrodynamics): soil-root-stem-canopy water fluxes interact with fast-timescale TFS biophysics by taking transpiration as a boundary condition and passing back the fraction of maximum conductance $\left(\mathrm{FMC}_{\mathrm{gs}}\right)$ for downregulating the next time step's stomatal conductance based on leaf water potential. Top right (size and trait scaling): hydraulic traits in leaves, stem, and roots are assigned based on each tree's height and trait values according to empirical equations and allometric theory described in this paper. Bottom right: TFS predicts a distribution of individual tree net primary productivities. See Supplement Fig. S1.1 for the structure of the plant hydraulics model.

module as it is implemented within TFS, and Fig. S1.1 in the Supplement can be referred to as the schematic of our hydraulics module.

\subsection{Plant hydraulics model}

\subsubsection{Overview}

In this section we highlight the important developments we made to the model developed by Sperry et al. (1998; hereafter S98). S98 consists of a discretization of the soil-plant continuum as a series of water storage compartments with defined heights, volumes, conducting areas, water retention, and conductivity properties, connected by elements with defined path lengths and conductances. Trees are divided into the four porous medium types of leaf, stem, transporting root, and absorbing root, with the stem being divided into a variable number of compartments and all other types consisting of a single compartment (Fig. S1.1). The soil is radially discretized with a variable number of compartments, or cylindrical "shells" around a characteristic absorbing root (the rhizosphere), and soil hydraulic properties are assumed constant across these compartments and across trees within a given soil type. The present TFS v.1-Hydro scheme does not consider the vertical distribution of soil water or roots. We anticipate this to be a key component for future model development when we incorporate this scheme into host models with variable soil depths.

The fast-timescale dynamics of the hydraulics model is governed by three sets of constitutive relationships: (1) the relationship between water potential and water content, (2) the relationship between hydraulic conductivity and water potential, and (3) the relationship between a stomatal water stress multiplier and leaf water potential. The first two relations are applied to every compartment within the plant-soil continuum and have specific equations for plant and soil porous media types. The soil constitutive equations for the first two relations are given by, respectively, the van Genuchten (1980) and Mualem (1976) formulations. We chose these particular equations for the soil water characteristic and unsaturated hydraulic conductivity because extensive work has parameterized these formulations on tropical soils, which have been noted to have distinct hydraulic prop- 
erties when compared to temperate soils of similar texture (Tomasella and Hodnett, 2002). These equations are given in Sect. 3.1.2 and 3.2.2 of Supplement S1. The plant constitutive equations for the first two relations are formulated and described in Sect. 2.1.2 and 2.1.3 below. The third relation for stomatal response to moisture stress is described in Sect. 2.1.5. All parameters of the constitutive relations for plant tissue are biologically interpretable and measurable plant hydraulic traits.

Several linkages are made between tree allometry and hydraulic properties (see Supplement S1 Sect. 4). Leaf, stem, transporting root, and absorbing root water storage compartment volumes derive respectively from the TFS-predicted leaf, stem, coarse-root, and fine-root biomasses using characteristic tissue densities. The heights of these components derived from tree height and rooting depth. The characteristic soil volume over which root uptake occurs is given by half the distance between absorbing roots, which decreases as total community root length (summed across all trees) increases. Total hydraulic conductance between adjacent plant water storage compartments is scaled from xylem hydraulic conductivity using first principles and plant allometric theory (Sect. 2.1.4). The model code only initializes these allometrically dependent hydraulic properties; it does not (yet) implement functions to update them as trees grow. Neglecting the effects of growth has negligible effects on the results presented in this paper but will be necessary for application of the model at timescales longer than 1 year.

The numerical solution (see Supplement S1 Sect. 5) operates at every time step (hourly) and updates water contents and potentials throughout the plant-soil continuum (including root uptake or loss) due to transpiration. It uses a first-order Taylor series expansion of the water content term to linearize the Richards mass balance equation describing the one-dimensional continuous array of plant and soil compartments. This results in a tridiagonal matrix that is solvable without iteration. Following the approach of Siqueira et al. (2008), infiltration and drainage are treated separately from the plant-soil fluxes due to transpiration (Supplement S1 Sect. 6).

\subsubsection{Tissue water relations}

We used PV theory (Tyree and Hammel, 1972; Tyree and Yang, 1990; Bartlett et al., 2012) to describe the constitutive relation between total water potential $\left(\psi_{\text {tot }}, \mathrm{MPa}\right)$ and relative water content (RWC; $\mathrm{g} \mathrm{H}_{2} \mathrm{O} \mathrm{g}^{-1} \mathrm{H}_{2} \mathrm{O}$ at saturation) in the plant compartments (Eq. 1). $\psi_{\text {tot }}$ is the sum of two components: solute potential $\psi_{\text {sol }}(\mathrm{MPa})$ which is negative due to the presence of solutes in living cells, and pressure potential $\psi_{p}$ (MPa) which is $\geq 0$ due to cell wall turgor (but see Ding et al., 2014). PV theory is usually applied to leaves, but can also apply to sapwood (Chapotin et al., 2006; Scholz et al., 2007; Meinzer et al., 2008b); thus, we apply it here to all plant tissue. Sapwood also stores capillary water (Tyree and
Yang, 1990) in its void spaces and embolized conduits. Consequently, this relation is described by three successive dehydration phases representing capillary water (sapwood only), elastic cell drainage (positive turgor), and continued drainage after cells have lost turgor:

$\psi_{\text {tot }}= \begin{cases}\psi_{0}-m_{\mathrm{cap}}(1-\mathrm{RWC}) & \mathrm{RWC}_{\mathrm{ft}} \leq \mathrm{RWC} \leq 1 \\ \psi_{\text {sol }}(\mathrm{RWC})+\psi_{p}(\mathrm{RWC}) & \mathrm{RWC}_{\mathrm{tip}} \leq \mathrm{RWC} \leq \mathrm{RWC}_{\mathrm{ft}} . \\ \psi_{\text {sol }}(\mathrm{RWC}) & \mathrm{RWC}_{\mathrm{r}} \leq \mathrm{RWC} \leq \mathrm{RWC}_{\mathrm{tip}}\end{cases}$

The first phase (capillary water) is assumed linear, characterized by a slope $\left(m_{\text {cap }}\right)$ and a saturated water potential $\left(\psi_{0}\right)$. The second elastic drainage phase has both solute $\left(\psi_{\mathrm{sol}}\right)$ and pressure $\left(\psi_{\mathrm{p}}\right)$ potential changing from the relative water content at which elastic drainage begins $\left(\mathrm{RWC}_{\mathrm{ft}}\right)$ up to the turgor loss point ( $\mathrm{RWC}_{\mathrm{tlp}}$ and corresponding $\psi=\pi_{\mathrm{tlp}}$ ), where $\psi_{p}=0$. In the final post-turgor loss phase, symplastic (cell water) and xylem water from embolized conduits are expressed up to the point at which $\psi_{\text {tot }}$ approaches $-\infty$ $\left(\mathrm{RWC}_{\mathrm{r}}\right) . \mathrm{RWC}_{\mathrm{r}}$ is often referred to as the apoplastic fraction (Bartlett et al., 2012), but in light of the considerable amount of water released when vessels embolize in stems (Tyree et al., 1991; Holtta et al., 2009), $\mathrm{RWC}_{\mathrm{r}}$ is best termed the residual fraction. Leaf PV curves as traditionally interpreted are a special case of Eq. (1) in which there is no capillary water $\left(\mathrm{RWC}_{\mathrm{ft}}=1\right) . \psi_{\mathrm{sol}}$ and $\psi_{p}$ are respectively given by

$\psi_{\mathrm{sol}}(\mathrm{RWC})=\psi_{\mathrm{sol}}\left(\mathrm{RWC}^{*}\right)=\frac{-\left|\pi_{\mathrm{o}}\right|}{\mathrm{RWC}^{*}}$,

$\psi_{p}(\mathrm{RWC})=\psi_{p}\left(R^{*}\right)=\left|\pi_{\mathrm{o}}\right|-\varepsilon R^{*}$,

where $\pi_{\mathrm{o}} \quad(\mathrm{MPa})$ and $\varepsilon(\mathrm{MPa})$ are osmotic potential at full turgor and bulk elastic modulus, respectively, and $\mathrm{RWC}^{*}=\left(\mathrm{RWC}-\mathrm{RWC}_{\mathrm{r}}\right) /\left(\mathrm{RWC}_{\mathrm{ft}}-\mathrm{RWC}_{\mathrm{r}}\right)$ and $R^{*}=$ $\left(\mathrm{RWC}_{\mathrm{ft}}-\mathrm{RWC}\right) /\left(\mathrm{RWC}_{\mathrm{ft}}-\mathrm{RWC}_{\mathrm{r}}\right)$ are transformations representing RWC and $R$ (relative water deficit; $1-\mathrm{RWC}$ ) of symplastic (cell) water only (Bartlett et al., 2012). The absolute mass $(W ; \mathrm{kg})$ of water in tissue is given by $W=$ $\rho_{\mathrm{w}} \theta_{\mathrm{sat}} R W C$, where $\theta_{\mathrm{sat}}\left(\mathrm{m}^{3} \mathrm{~m}^{-3}\right)$ is the maximum water content on a per volume basis (or porosity) and $\rho_{\mathrm{W}}$ $\left(\mathrm{kg} \mathrm{m}^{-3}\right)$ is the density of water. The constitutive equations used in the model are, in terms of volumetric water content $\left(\theta ; \mathrm{m}^{3} \mathrm{H}_{2} \mathrm{O} \mathrm{m}^{-3}\right.$ plant tissue), achievable by using the transformations given above (see Supplement S1). Volumetric capacitance $\left(C ; \mathrm{kg} \mathrm{m}^{-3} \mathrm{MPa}^{-1}\right)$ is defined at any point along the three regions as $\left(\rho_{\mathrm{w}} \theta_{\mathrm{sat}} \frac{\mathrm{dRWC}}{\mathrm{d} \psi}\right)$, which for sapwood is the highest in the capillary region $(\sim 200$ $\left.400 \mathrm{~kg} \mathrm{~m}^{-3} \mathrm{MPa}^{-1}\right)$, intermediate in the elastic region $(20$ $200 \mathrm{~kg} \mathrm{~m}^{-3} \mathrm{MPa}^{-1}$ ) (Tyree and Yang, 1990), and, after an initial increase beyond the turgor loss point, in theory will approach zero as $\mathrm{RWC} \rightarrow \mathrm{RWC}_{\mathrm{r}}$. Henceforth and in all figures, we report $C$ at full turgor $\left(C_{\mathrm{ft}}\right)$, defined as the change in water mass per unit volume per unit change in water potential over the region where cell turgor $\left(\psi_{p}\right) \geq 0$ $\left(\left.C_{\mathrm{ft}} \equiv \rho_{\mathrm{w}} \theta_{\mathrm{sat}} \frac{\Delta \mathrm{RWC}}{\Delta \psi}\right|_{\mathrm{RWC}=1} ^{\mathrm{RWC}=\mathrm{RWC}_{\mathrm{tlp}}}\right)$. For these hydraulic traits and all others which follow, we denote specific reference to 
leaf and xylem (sapwood) tissue with the subscripts 1 and $x$, respectively. Key hydraulic PV traits which we seek to determine as functions of more commonly measured plant traits are $\varepsilon, \pi_{\mathrm{o}}, \mathrm{RWC}_{\mathrm{tlp}}, C_{\mathrm{ft}}$, and $\mathrm{RWC}_{\mathrm{r}}$.

\subsubsection{Embolism vulnerability}

We use the inverse polynomial of Manzoni et al. (2013a) for the xylem vulnerability curve, termed here the "fraction of maximum conductivity" for xylem $\left(\mathrm{FMC}_{\mathrm{x}}\right)$ :

$\mathrm{FMC}_{\mathrm{x}}\left(\psi_{\mathrm{x}}\right)=\left[1+\left(\frac{\psi_{\mathrm{x}}}{P_{50, \mathrm{x}}}\right)^{a_{\mathrm{x}}}\right]^{-1}$,

where $P_{50, \mathrm{x}}$ is the water potential at which $50 \%$ of maximum conductance is lost and $a_{\mathrm{x}}$ is a shape parameter (unitless). $\mathrm{FMC}_{\mathrm{X}}$ is defined at compartment nodes and is a nondimensional multiplier bounded on $(0,1]$ limiting the maximum xylem conductance $\left(K_{\max , i} ; \mathrm{kg} \mathrm{s}^{-1} \mathrm{MPa}^{-1} ; \mathrm{FMC}_{\mathrm{x}}=1\right.$ and 0 indicate no and complete xylem embolism) between any two compartments $i$ and $i+1$. Section 1 of the Supplement outlines how $\mathrm{FMC}_{\mathrm{x}}$, defined at compartment nodes, limits $K_{\max , i}$, which is defined at compartment boundaries. Critically, $K_{\max , i}$ derives from plant hydraulic architecture and maximum xylem-specific conductivity $\left(k_{\mathrm{s}, \max , \mathrm{x}}\right)$. Because $k_{\mathrm{s}, \max , \mathrm{x}}$ relates to the maximum rate at which water can be transported through the xylem, and $P_{50, \mathrm{x}}$ quantifies the xylem water potential at which half of this transport capacity is lost, these can be thought as representing xylem efficiency and safety, respectively. "Safety" refers to a property of the xylem alone and is not to be confused with the hydraulic safety margin (HSM), which is field-observed or modeled minimum leaf water potential relative to $P_{50, \mathrm{x}}$. As with PV traits, we seek to determine to what extent xylem efficiency and safety covary with other plant traits and trade off with each other.

\subsubsection{Scaling conductance with tree size}

Tree size exhibits a first-order control over much of the variation in whole-plant hydraulic conductance (Sperry et al., 2008) since hydraulic path length increases with tree height $(H)$ (Mencuccini, 2002). For this reason, wholeplant conductance is not a constant parameter in our model. Rather, first principles dictate that, to a first approximation, whole-tree maximum aboveground conductance ( $\left.K_{\text {max,tree,ag }} ; \mathrm{kg} \mathrm{s}^{-1} \mathrm{MPa}^{-1}\right)$ may be derived as a function of xylem conductivity $\left(k_{\mathrm{s}, \max , \mathrm{x}} ; \mathrm{kg} \mathrm{m}^{-1} \mathrm{~s}^{-1} \mathrm{MPa}^{-1}\right)$, sapwood area $\left(A_{\mathrm{s}} ; \mathrm{m}^{-2}\right)$, and $H(\mathrm{~m})$ as

$K_{\text {max,tree,ag }}=\frac{k_{\mathrm{s}, \max , \mathrm{x}} A_{\mathrm{s}}}{H}$.

This relation predicts the negative effects of $H$ (increasing $H$ means decreasing $K_{\text {max,tree,ag }}$ ). Whole-tree conductance per unit leaf area $\left(K_{1, \text { max,tree,ag }}\right)$ will determine water status at the level of individual leaves, and thus hydraulic constraints on leaf-level gas exchange. Dividing through by leaf area $\left(A_{1}\right.$; $\mathrm{m}^{2}$ ) gives

$K_{1, \text { max }, \text { tree, ag }}=\frac{k_{\mathrm{s}, \max , \mathrm{x}} A_{\mathrm{s}}}{H A_{1}}$.

In this relation, the leaf:sapwood area ratio $\left(A_{1}: A_{\mathrm{S}}\right)$

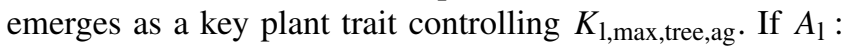
$A_{\mathrm{s}}$ decreases with tree height, as has been documented in many tree species (McDowell et al., 2002; also see CalvoAlvarado et al., 2008), the negative effects of height can be partially overcome. In addition, the near-universal tendency for xylem conduits to decrease in diameter within trees from trunk base to stem tips (Mencuccini et al., 2007; Meinzer et al., 2010; Petit and Anfodillo, 2011; Olson and Rosell, 2013; Olson et al., 2014) also mitigates the negative effects of height according to the Hagen-Poiseuille law. Neglecting the effects of xylem taper may thus overestimate the negative hydraulic effects of increasing path length in sizestructured forests. Metabolic scaling theory (MST) makes baseline predictions about the optimal degree of xylem conduit taper in trees subject to the constraint of hydraulic safety (which decreases as conduits get larger) and has been validated against observations of conduit diameter across trees of different heights (West et al., 1999; Savage et al., 2010). We therefore use MST to include the effect of xylem taper on

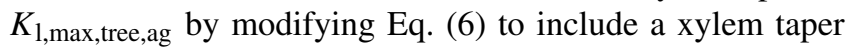
term $\left(\chi_{\text {tap }: \text { notap,ag }}\right.$; unitless $)$ representing the ratio of wholeplant conductance with taper to that without:

$K_{1, \text { max,tree,ag }}=\frac{k_{\mathrm{s}, \text { max,petiole }} A_{\mathrm{s}}}{H A_{1}} \chi_{\mathrm{tap}: \text { notap,ag }}$,

where $k_{\mathrm{s} \text {,max,petiole }}\left(\mathrm{kg} \mathrm{m}^{-1} \mathrm{~s}^{-1} \mathrm{MPa}^{-1}\right)$ is used to reference $K_{1, \text { max,tree,ag }}$ to MST predictions. $\chi_{\text {tap : notap,ag }}$ is in the range of 23-50 for trees of heights $10-30 \mathrm{~m}$; thus, the benefit of xylem taper for increasing total plant conductance itself increases with tree height. $\chi_{\text {tap } \text { : notap }}$ is assumed constant across individuals in this study, but parameterizing variation in $A_{1}$ : $A_{\mathrm{s}}$ across species is an outcome of this study. The full details of this approach in addition to the treatment of the belowground component of tree conductance $\left(K_{\text {max,tree,bg }}\right)$ are outlined in Sect. 2 of the "Technical description" (Supplement S1).

\subsubsection{Hydraulic impacts on stomatal conductance}

The fraction of maximum stomatal conductance $\left(\mathrm{FMC}_{\mathrm{gs}}\right.$; $[0,1])$, which is updated at every time step and is used to downregulate non-water stressed stomatal conductance (sensu Jarvis, 1976), is one of two variables passed from the hydraulics module to the host model TFS. As in Mencuccini et al. (2015), the formulation for $\mathrm{FMC}_{\mathrm{gs}}$ mimics the loss of xylem conductivity with water potential relation:

$g_{\mathrm{s}}=g_{\mathrm{s}, \max } \times \mathrm{FMC}_{\mathrm{gs}}=g_{\mathrm{s}, \max }\left[1+\left(\frac{\psi_{1}}{P_{50, \mathrm{gs}}}\right)^{a_{\mathrm{gs}}}\right]^{-1}$, 
where $P_{50, \mathrm{gs}}$ and $a_{\mathrm{gs}}$, respectively, represent leaf water potential at $50 \%$ stomatal closure and the slope of the curve at $\psi_{1}=P_{50, \mathrm{gs}}$, and $g_{\mathrm{s}, \max }$ is stomatal conductance in the absence of water supply limitation and comes from the host model's stomatal conductance scheme (for TFS, we used Medlyn et al., 2011; see Eq. A25 of Fyllas et al., 2014). The second variable passed from the hydraulics module to the TFS model describes the derivative of $\mathrm{FMC}_{\mathrm{gs}}$ with leaf water content, which is derived from the $\mathrm{FMC}_{\mathrm{gs}} \sim \psi_{1}$ (Eq. 8) and leaf pressure-volume (Eqs. 1-3) relations (see Eqs. S34a and S40 in the Supplement S1 for derivation). This variable is used as an additional constraint promoting stability within the numerical solution (see Sect. 5.3 of the Supplement S1 and Supplement S3 Fig. S3.3).

Theory and data suggest that stomata operate in such a way as to prevent catastrophic xylem embolism (Sperry and Love, 2015); this implies that $P_{50, \mathrm{gs}}>P_{50, \mathrm{x}}$, which is supported by global datasets (Klein, 2014; Manzoni et al., 2013b). We used a $1: 1$ relationship between $P_{50, \mathrm{gs}}$ and the water potential at $20 \%$ loss of xylem hydraulic conductivity $\left(P_{20, \mathrm{x}}\right)$, a relationship suggested by data from a tropical dry forest (Brodribb et al., 2003). $P_{20, \mathrm{x}}$ is easily derived from $P_{50, \mathrm{x}}$ and $a_{\mathrm{x}}$ using Eq. (4). This current approach ignores the continuum in hydraulic safety (Klein, 2014; Martinez-Vilalta et al., 2014; Skelton et al., 2015) and future work needs to identify how such a continuum maps onto other plant traits. $a_{\mathrm{gs}}$ is derived from $P_{50, \mathrm{gs}}$ using the same relationship derived for $a_{\mathrm{x}}$ and $P_{50, \mathrm{x}}$ (Table 2).

\subsection{Host model TFS}

The TFS (Fyllas et al., 2014) is an individual tree model parameterized from plot-level observed tree size distribution and distributions of the four plant traits: WD, LMA, $\mathrm{N}_{\mathrm{L}}$, and $P_{L}$. These traits are assigned to each individual upon initialization in a way that preserves the underlying observed joint distribution of all four traits (be it tight or weak coupling among traits), which are then used to parameterize plant physiological parameters for each tree in a stand (Fig. 1). WD in TFS v.1 drives differential rates of stem respiration and stem $\mathrm{C}$ allocation, and LMA, $\mathrm{N}_{\mathrm{L}}$, and $\mathrm{P}_{\mathrm{L}}$ jointly drive differential rates of leaf light-saturated photosynthesis (photosynthetic capacity, $A_{\max }$ ) via parameterization of photosynthetic parameters $V_{\mathrm{c}, \max }$ and $J_{\max }$ (Domingues et al., 2010), in addition to respiration and leaf and stem $\mathrm{C}$ allocation. The construction of this model was motivated by a need to diagnose large-scale patterns of productivity and turnover in tropical forests that, among other drivers, implicate a link to soil fertility and, more proximally, plant traits reflective of fertility differences (Baker et al., 2004; Fyllas et al., 2009; Patiño et al., 2012; Quesada et al., 2012; Johnson et al., 2016). Because measurements of stand-level variation in easily measured plant traits are much more abundant than comparative measures of hydraulic traits, we sought to parameterize
Table 1. Input tree size and leaf and stem traits used by the TFS model.

\begin{tabular}{lll}
\hline Trait & Symbol & Units \\
\hline Tree height & $H$ & $\mathrm{~m}$ \\
Tree diameter at breast height & $\mathrm{DBH}$ & $\mathrm{cm}$ \\
Leaf mass per area & $\mathrm{LMA}$ & $\mathrm{g} \mathrm{m}^{-2}$ \\
Leaf nitrogen & $\mathrm{N}_{\mathrm{L}}$ & $\mathrm{mg} \mathrm{g}^{-1}$ \\
Leaf phosphorus & $\mathrm{P}_{\mathrm{L}}$ & $\mathrm{mg} \mathrm{g}^{-1}$ \\
Light-saturated photosynthesis rate & $A_{\max }$ & $\mu \mathrm{mol} \mathrm{m}^{-2} \mathrm{~s}^{-1}$ \\
Wood density & $\mathrm{WD}$ & $\mathrm{g} \mathrm{cm}^{-3}$ \\
\hline
\end{tabular}

hydraulic trait variation via empirical relationships with the four TFS traits (see Table 1 and Sect. 3.1 below).

A second key component of TFS is the representation of stand structure and hence individual-level variation in tree crown light environments, which is an additional key determinant of ecosystem productivity (Stark et al., 2012) and, as we will show, individual-level variation in tree hydraulic function and limitation. To estimate the light environment for each tree, TFS uses the perfect plasticity approximation (PPA) of Purves et al. (2007) and Strigul et al. (2008), updated to represent multiple canopy layers typical of tropical forests (Bohlmann and Pacala, 2012) as well as basic gap dynamics that allow for a fraction of small trees to receive full sunlight (Fauset et al., unpublished manuscript).

In conclusion, TFS couples individual-level variation in plant traits and light environments with a full canopy biophysics scheme for estimating photosynthesis and transpiration for each tree $>10 \mathrm{~cm}$ DBH in a stand. Transpiration is the necessary boundary condition for our new plant hydraulics module (Fig. 1). For further details on TFS biophysics, size structure, trait parameterization, and light competition, see Fyllas et al. (2014) and references therein.

\section{Methods}

\subsection{Hydraulic trait synthesis for parameterization of plant hydraulics model}

We synthesized the literature and existing trait databases and asked whether hydraulic traits associated with PV curves in leaves $\left(\pi_{\mathrm{o}, 1}, \varepsilon_{1}, \mathrm{RWC}_{\mathrm{tlp}, 1}\right.$, and $\left.\mathrm{RWC}_{\mathrm{r}, 1}\right)$ and sapwood $\left(\pi_{\mathrm{o}, \mathrm{x}}\right.$, $\varepsilon_{\mathrm{x}}, \mathrm{RWC}_{\mathrm{tlp}, \mathrm{x}}$, and $\mathrm{RWC}_{\mathrm{r}, \mathrm{x}}$ ), xylem conductivity per unit sapwood area $\left(k_{\mathrm{s}, \max , \mathrm{x}}\right)$ or per unit leaf area $\left(k_{1, \max , \mathrm{x}}\right)$, xylem resistance to embolism $\left(P_{50, \mathrm{x}}\right)$, and associated shape parameter $\left(a_{\mathrm{x}}\right)$ as well as hydraulic architecture $\left(A_{1}: A_{\mathrm{s}}\right)$ were coordinated with the leaf and stem traits employed as input by the TFS model. All statistical analyses were carried out within the R language (R Core Team, 2015).

For leaf PV traits and LMA, we started with the Bartlett et al. (2012) database subset for tropical ecosystems (111 individuals across 14 studies) and added substantial additional 
Table 2. Hydraulic traits used by the model. Resultant empirical "ecotransfer" function which estimates hydraulic traits as a function of input traits and its corresponding source.

\begin{tabular}{|c|c|c|c|c|}
\hline Parameter & Symbol & Units & Empirical ecotransfer function & Source \\
\hline $\begin{array}{l}\text { Leaf-saturated water } \\
\text { content }\end{array}$ & $\theta_{\mathrm{s}, 1}$ & $\mathrm{~m}^{3} \mathrm{~m}^{-3}$ & $\frac{-2.32 \times 10^{4} / \mathrm{LMA}+782}{\rho_{\mathrm{w}}}\left(\frac{1}{-0.21 \ln \left(10^{4} / \mathrm{LMA}\right)+1.43}-1\right)$ & $\begin{array}{l}\text { Stewart et al. (1990), } \\
\text { L. Rowland and } \\
\text { B. Christoffersen } \\
\text { (unpublished data) }\end{array}$ \\
\hline $\begin{array}{l}\text { Leaf osmotic poten- } \\
\text { tial at full turgor }\end{array}$ & $\pi_{\mathrm{o}, 1}$ & $\mathrm{MPa}$ & $-0.04-1.51 \mathrm{WD}-0.0067 \mathrm{LMA}$ & This study \\
\hline $\begin{array}{l}\text { Leaf osmotic poten- } \\
\text { tial at turgor loss }\end{array}$ & $\pi_{\mathrm{tlp}, 1}$ & $\mathrm{MPa}$ & $\frac{\varepsilon_{\mathrm{X}} \pi_{\mathrm{o}, 1}}{\varepsilon_{\mathrm{X}}+\pi_{\mathrm{o}, 1}}$ & Bartlett et al. (2012) \\
\hline $\begin{array}{l}\text { Leaf bulk elastic } \\
\text { modulus }\end{array}$ & $\varepsilon_{1}$ & $\mathrm{MPa}$ & $2.5+\frac{37.5}{1+e^{-8.0 \mathrm{WD}+5.7}}$ & This study \\
\hline $\begin{array}{l}\text { Leaf relative water } \\
\text { content at turgor loss }\end{array}$ & $\mathrm{RWC}_{\mathrm{tlp}, 1}$ & - & $\frac{\left(\pi_{0,1}\left(1-\mathrm{RWC}_{\mathrm{r}, 1}\right)+\varepsilon_{1}\right)}{\varepsilon_{1}}$ & Bartlett et al. (2012) \\
\hline Leaf residual fraction & $\mathrm{RWC}_{\mathrm{r}, 1}$ & - & $0.01 \varepsilon_{1}+0.17$ & This study \\
\hline 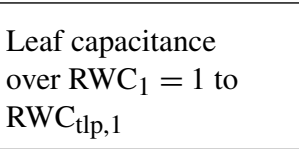 & $C_{\mathrm{ft}, 1}$ & $\begin{array}{l}\mathrm{g} \mathrm{H}_{2} \mathrm{Og}^{-1} \\
\text { dry weight } \\
\mathrm{MPa}^{-1}\end{array}$ & $\frac{\rho_{\mathrm{W}} \theta_{\mathrm{s}, \mathrm{l}}\left(1-\mathrm{RWC}_{\mathrm{r}, \mathrm{l}}\right)\left(\varepsilon_{1}+\pi_{\mathrm{o}, \mathrm{l}}\right)}{\varepsilon_{1}^{2}}$ & Bartlett et al. (2012) \\
\hline $\begin{array}{l}\text { Sapwood-saturated } \\
\text { water content }\end{array}$ & $\theta_{\mathrm{s}, \mathrm{x}}$ & $\mathrm{m}^{3} \mathrm{~m}^{-3}$ & $1-\frac{\mathrm{WD}}{1.54}$ & Siau (1984) \\
\hline $\begin{array}{l}\text { Sapwood RWC at } \\
\text { which capillary } \\
\text { reserves exhausted }\end{array}$ & $\mathrm{RWC}_{\mathrm{ft}, \mathrm{x}}$ & - & $1-0.72\left(1-\mathrm{RWC}_{\mathrm{tl}, \mathrm{x}}\right)$ & This study \\
\hline $\begin{array}{l}\text { Fraction of } 1-r_{f, 2} \\
\text { that is capillary in } \\
\text { source }\end{array}$ & $f_{\text {cap }}$ & - & 0.07 & This study \\
\hline $\begin{array}{l}\text { Sapwood osmotic } \\
\text { potential at full turgor }\end{array}$ & $\pi_{0, x}$ & $\mathrm{MPa}$ & $0.52-4.16 \times \mathrm{WD}$ & This study \\
\hline $\begin{array}{l}\text { Sapwood osmotic } \\
\text { potential at turgor loss }\end{array}$ & $\pi_{\mathrm{tlp}, \mathrm{x}}$ & $\mathrm{MPa}$ & $\frac{\varepsilon_{\mathrm{x}} \pi_{\mathrm{o}, \mathrm{x}}}{\varepsilon_{\mathrm{X}}+\pi_{\mathrm{o}, \mathrm{x}}}$ & Bartlett et al. (2012) \\
\hline $\begin{array}{l}\text { Sapwood bulk elastic } \\
\text { modulus }\end{array}$ & $\varepsilon_{\mathrm{X}}$ & $\mathrm{MPa}$ & $\sqrt{1.02 e^{8.5 \mathrm{WD}}-2.89}$ & This study \\
\hline $\begin{array}{l}\text { Sapwood RWC at } \\
\text { turgor loss }\end{array}$ & $\mathrm{RWC}_{\mathrm{tlp}, \mathrm{x}}$ & - & $1-\frac{(1-0.75 \times \mathrm{WD})}{(2.74+2.01 \times \mathrm{WD})}$ & This study \\
\hline $\begin{array}{l}\text { Sapwood residual } \\
\text { fraction }\end{array}$ & $\mathrm{RWC}_{\mathrm{r}, \mathrm{x}}$ & - & $\frac{\varepsilon_{\mathrm{X}}\left(1-f_{\mathrm{cap}}-\mathrm{RWC}_{\mathrm{tlp}, \mathrm{x}}\right)}{\pi_{\mathrm{o}, \mathrm{x}}\left(1-f_{\text {cap }}\right)}+1-\varepsilon_{\mathrm{X}} f_{\text {cap }}$ & This study \\
\hline $\begin{array}{l}\text { Sapwood capacitance } \\
\text { over } \mathrm{RWC}_{1}=1 \text { to } \\
\mathrm{RWC}_{\mathrm{tlp}, 1}\end{array}$ & $C_{\mathrm{ft}, \mathrm{x}}$ & $\begin{array}{l}\mathrm{kg} \mathrm{m}^{-3} \\
\mathrm{MPa}^{-1}\end{array}$ & $\frac{\rho_{\mathrm{w}} \theta_{\mathrm{s}, \mathrm{x}}\left(1-\mathrm{RWC}_{\mathrm{r}, \mathrm{x}}\right)\left(\varepsilon_{\mathrm{x}}+\pi_{\mathrm{o}, \mathrm{x}}\right)\left(\pi_{\mathrm{o}, \mathrm{x}}\left(1-f_{\mathrm{cap}}\right)-\varepsilon_{\mathrm{x}} f_{\mathrm{cap}}\right)}{\pi_{\mathrm{o}, \mathrm{x}} \varepsilon_{\mathrm{x}}^{2}}$ & This study \\
\hline $\begin{array}{l}\text { Xylem water potential } \\
\text { at } 50 \% \text { loss of } \\
\text { conductivity }\end{array}$ & $P_{50, \mathrm{x}}$ & $\mathrm{MPa}$ & $-(3.57 \mathrm{WD})^{1.73}-1.09$ & This study \\
\hline $\begin{array}{l}\text { Slope of xylem vul- } \\
\text { nerability curve at } \\
P_{50}\end{array}$ & $a_{\mathrm{x}}$ & $\begin{array}{l}\mathrm{MPa}^{-1} \times \\
100\end{array}$ & $54.4\left(-P_{50, \mathrm{x}}\right)^{-1.17}$ & This study \\
\hline
\end{tabular}


Table 2. Continued.

\begin{tabular}{lllll}
\hline Parameter & Symbol & Units & Empirical “ecotransfer” function & Source \\
\hline $\begin{array}{l}\text { Maximum xylem } \\
\text { conductivity per unit } \\
\text { leaf area }\end{array}$ & $k_{1, \mathrm{max}, \mathrm{x}}$ & $\begin{array}{l}\mathrm{kg} \mathrm{m}^{-1} \\
\mathrm{~s}^{-1} \mathrm{MPa}^{-1}\end{array}$ & $0.0021 e^{-26.6 \mathrm{WD} / A_{\max }}$ & This study \\
\hline $\begin{array}{l}\text { Maximum xylem } \\
\text { conductivity per unit } \\
\text { sapwood area }\end{array}$ & $k_{\mathrm{s}, \mathrm{max}, \mathrm{x}}$ & $\begin{array}{l}\mathrm{kg} \mathrm{m}^{-1} \\
\mathrm{~s}^{-1} \mathrm{MPa}^{-1}\end{array}$ & $\frac{k_{1, \mathrm{max}, \mathrm{x}}}{A_{\mathrm{l}} A_{\mathrm{s}}}$ & This study \\
\hline $\begin{array}{l}\text { Leaf to sapwood area } \\
\text { ratio }\end{array}$ & $A_{1}: A_{\mathrm{s}}$ & $\mathrm{m}^{2} \mathrm{~cm}^{-2}$ & $546 \mathrm{LMA}^{-2.14} H$ & This study \\
\hline $\begin{array}{l}\text { Leaf- to fine-root } \\
\text { absorbing surface area } \\
\text { ratio }\end{array}$ & $A_{1}: A_{\mathrm{r}}$ & $\mathrm{m}^{2} \mathrm{~m}^{-2}$ & 1 & This study \\
\hline
\end{tabular}

data (44 individuals across 12 studies) through further literature review, and joined to this dataset species-averaged values of wood density using the Global Wood Density Database (Chave et al., 2009; Zanne et al., 2009). For sapwood PV traits, we generated our own database (33 specimens across 9 studies) by digitizing data points of $\mathrm{RWC}_{\mathrm{X}} \mathrm{Vs}$. $\psi_{\mathrm{X}}$ conducted on trunk or branch tissue from published figures using WebPlotDigitizer (Rohatgi, 2014), and fit curves to these plots following established methods for extracting PV parameters (Tyree and Hammel, 1972; Sack and PasquetKok, 2011; Bartlett et al., 2012). We found significant differences in the shape of curve and magnitude of capacitance for sapwood PV curves conducted on small trunk cores vs. cut whole terminal branches, with trunk cores yielding capacitance 2-10 times that of branches, suggesting substantial artifact-associated measurements conducted on trunk cores, an issue recently highlighted by Wolfe and Kursar (2015). Using measurements made on the same species using both methods, we developed a correction procedure and applied it to data suffering this bias (Christoffersen, unpublished manuscript), and provide versions of figures without the correction applied in the Supplement S2.

For analyzing relations between xylem efficiency and safety and other traits, we started with the Xylem Functional Traits (XFT) database (Choat et al., 2012; Gleason et al., 2016), subset to tropical regions and added data from 15 additional species not originally present (Mendez-Alonzo et al., 2012). We then evaluated the hypothesis that variation in hydraulic transport is explained by WD by prioritizing WD reported in the original publications and adding species-averaged WD data from Zanne et al. (2009) where it was unreported. We also evaluated the hypothesis that rates of hydraulic transport coordinate with leaf-level rates of gas exchange. Because the objective of this paper is to derive hydraulic traits from other non-hydraulic plant traits, we explored the relationship of $k_{\mathrm{s}, \max , \mathrm{x}}$ regressed on the light-saturated photosynthesis rate $\left(A_{\max }\right)$, even though the causality of the relationship could be interpreted in reverse. There is substantial debate surrounding appropriate methods for determining embolism vulnerability (Choat et al., 2010; Cochard et al., 2010; Sperry et al., 2012; Wang et al., 2014) (see Brodribb et al., 2016 for a brief summary). Because there is some consensus that the "gold standard" for $P_{50, \mathrm{x}}$ measurements involves bench dehydration (DH) on longstem segments (Jansen et al., 2015), we explored trait relationships with and without other measurement methods for $P_{50, \mathrm{x}}$.

For hydraulic architecture, we used the only study of which we were aware for tropical trees (Calvo-Alvarado et al., 2008), which reports independent measurements of individual total tree leaf area and sapwood area across a wide range of tree sizes to explore the relationship of $A_{1}: A_{\mathrm{S}}$ with tree height as well as with LMA, and verified the latter relationship using a much broader dataset of branch-level measurements of $A_{1}: A_{\mathrm{s}}$ conducted across the Amazon basin (Patiño et al., 2012). Via literature survey, we also compiled an independent, extensive dataset of $A_{\mathrm{s}}$ as it varied with tree $\mathrm{DBH}(\mathrm{cm})$ in tropical forests.

Finally, we standardized the representation of the "biome" category across all databases, and defined the following categories based on the location of the study (not the species' home range): tropical flooded forest (if identified as such in original publication), tropical wet forest (no months where evaporative demand exceeds precipitation), tropical moist forest (at least 1 month where evaporative demand exceeds precipitation; predominantly evergreen), tropical dry forest (drought-deciduous phenologies make up a substantial fraction of species), tropical savanna (identified as such in original publication), subtropical forest (absolute latitude exceeded $23^{\circ}$ ), tropical mangrove, and greenhouse. Syntheses of traits were limited to studies conducted on species growing in native (non-greenhouse) environments in tropical (thus excluding subtropical observations) upland (nonflooded) habitats. In some cases, it was also necessary to 
match hydraulic traits for the same species given as multiple (different) records within a database. As a rule, however, we did not average to the species level, and thus some variation included in regressions is intraspecific, albeit small.

\subsection{Model setup}

We used Princeton downscaled meteorological forcing data (Sheffield et al., 2006), observed soil textural properties, and observed tree size and trait distributions (for WD, LMA, $\mathrm{N}_{\mathrm{L}}$, and $\mathrm{P}_{\mathrm{L}}$ ) in the Caxiuana National Forest of east-central Brazilian Amazonia, a seasonal evergreen forest receiving 2100-2500 mm of rainfall annually (Meir et al., 2008; da Costa et al., 2010; Meir et al., 2015; Rowland et al., 2015a, c), to parameterize and run our model for 1 year. Spin-up was not necessary, as the model was initialized from plot observations as described above, and an initial soil moisture was chosen typical of wet season conditions, which is when the model period began. While actual soil depth at the site is $\sim 10 \mathrm{~m}$, we set soil depth in simulations to $4 \mathrm{~m}$, which reflects the effective depth over which the majority of water extraction occurs, based on previous model validation with soil moisture data (Fisher et al., 2007). This setup applied to all model simulations in this paper - both the model experiments and the simulations for comparison with field data.

\subsection{Model experiments}

We conducted two sets of model experiments designed to explore the impacts of the new plant hydraulics scheme on simulated tree transpiration. In both cases, the TFS model was run with (TFS v.1-Hydro) and without (TFS v.1) the new plant hydraulics scheme. In the first experiment, all trees were assigned identical trait values using plot-mean values of WD, LMA, $\mathrm{N}_{\mathrm{L}}$, and $\mathrm{P}_{\mathrm{L}}$. Plant hydraulic traits were identical across individuals in TFS v.1-Hydro. Having eliminated plant hydraulic traits as a source of variation among simulated tree transpiration, we used this model experiment to explore the impact of plant hydraulics on transpiration dynamics as a function of tree height and canopy position. To explore the consequence of trait variation independent of height and canopy position, our second experiment set varied a single trait $\left(\mathrm{P}_{\mathrm{L}}, \mathrm{WD}\right.$, or LMA), by resampling the observed plot trait distributions of these traits following the algorithm of Taylor and Thompson (1986) (see Fyllas et al., 2014 for a full description of this resampling method as implemented in TFS), keeping all other traits at the plot-mean value. We then explored the dynamics of transpiration, for canopy trees (full sunlight) only, of three large $(50-55 \mathrm{~cm} \mathrm{DBH})$ trees spanning the range of assigned trait values. In both model experiments, we examined the simulated mean diurnal cycle of transpiration characteristic of the wet and dry season, defined as months where monthly precipitation exceeded or fell below $100 \mathrm{~mm}$, respectively. Months at season boundaries were excluded to maximize seasonal differences.

\subsection{Model evaluation}

Separate from and in addition to the model experiments, we performed three sets of model evaluation that assessed the model's ability to capture observed variations in transpiration and water potential at the individual tree level and the stand level. In the first evaluation set, we evaluated diurnal cycles of leaf and stem water potential across multiple individual trees spanning a wide range of sizes and canopy positions, which were also subject to seasonal differences in light and water availability. In this set, all individual trees possessed identical (plot-mean) trait values. We matched simulated trees to those measured by Fisher et al. (2006) on the basis of size (see Table 3) across replicate days in the month matching the month in which observations were made (May for wet season, November for dry season), taking the standard error of the mean as the model error. A total of four individual tree comparisons were made.

The second evaluation set was similar to the first, except we focused on midday simulated leaf water potentials. We conducted four distinct sets of model simulations in which we explored how successive changes to model parameterization impacted model fidelity with the observations. The first model simulation assigned trees identical trait values, equal to the plot mean, and made no accounting of xylem conduit taper (following Eq. 6). The second model simulation was like the first, except this time accounting for xylem conduit taper (following Eq. 7). The third simulation was like the second but adjusted the canopy position of two of the simulated individuals. The fourth simulation was like the third but adjusted the stomatal sensitivity parameter $P_{50, \mathrm{gs}}$ for a single tree to be less sensitive to leaf water potential by changing its value from -2.9 to $-5.0 \mathrm{MPa}$.

In the final set, we evaluated seasonal differences in standscaled sap flux. We used model setups in which all individuals possessed identical hydraulic traits and where all individuals possessed different traits according to the plot observed trait distributions in order to assess ecosystem-level consequences of plant trait variation. Each of these setups was run as TFS v.1 and TFS v.1-Hydro. For comparison with observations, simulated individual total transpiration $\left(\mathrm{kg} \mathrm{s}^{-1}\right)$ was summed across individuals, divided by the plot area, and accumulated for each month of the year. Observed stand-level transpiration was derived following the methods outlined in Fisher et al. (2007).

\section{Results}

\subsection{Hydraulic trait synthesis for parameterization of plant hydraulics model}

\subsubsection{Hydraulic trait synthesis}

All resultant empirical equations concerning traits WD, LMA, or $A_{\max }$ to hydraulic traits are given in Table 2. 

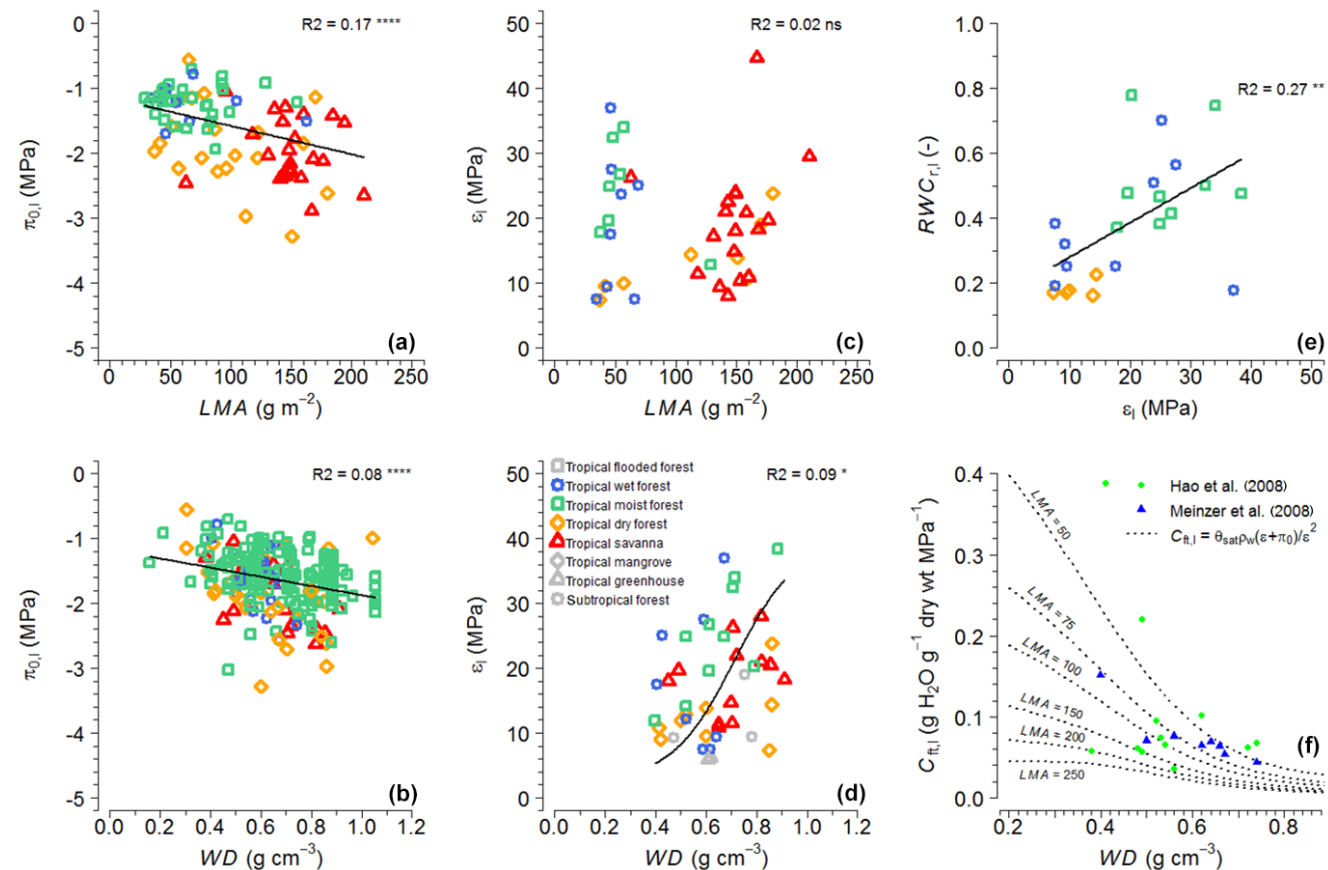

Figure 2. Tropical synthesis of leaf PV parameters in relation to leaf mass per area (LMA), wood density (WD), or each other. (a, b) Leaf osmotic potential at full turgor $\left(\pi_{\mathrm{o}, 1}\right)$ in relation to LMA and WD; $(\mathbf{c}, \mathbf{d})$ leaf bulk elastic modulus $\left(\varepsilon_{1}\right)$ in relation to LMA and WD; (e) residual fraction $\left(\mathrm{RWC}_{\mathrm{r}, 1}\right)$ in relation to $\varepsilon_{1}$; and (f) capacitance $\left(C_{\mathrm{ft}, 1}\right)$ in relation to LMA (different lines) and WD. LMA and WD values come first from published values and are supplemented with species-averaged values from GLOPNET (Wright et al., 2004) and the global wood density database (Zanne et al., 2009). The following asterisk codes denote statistical significance at $\alpha$ levels of $0.05,0.01,0.001$, and 0.0001 , respectively, ${ }^{*}, * *, * * *, * * * *$.

For leaf PV traits (Fig. 2), we found highly significant $(p<0.0001)$ but weak negative relationships of $\pi_{0,1}$ (leaf osmotic potential at full turgor) with both WD and LMA $\left(r^{2}=0.28\right.$ and 0.09 , respectively). Because WD and LMA were not significantly correlated in this dataset $(p=0.48)$, we used them as independent predictors of $\pi_{0,1}$ in multiple regression and were able to explain a higher fraction of the variance in $\pi_{\mathrm{o}, 1}\left(r^{2}=0.44\right.$; see Table 2$)$. Surprisingly, $\varepsilon_{1}$ (leaf bulk elastic modulus) demonstrated no significant relationship with LMA but was marginally correlated with WD $\left(p<0.05 ; r^{2}=0.10\right.$; Fig. $\left.2 c, d\right)$. While we found no significant relationship of the residual fraction $\left(\mathrm{RWC}_{\mathrm{r}, 1}\right)$ with $\mathrm{LMA}$ or WD, we did find a significant relationship of $\mathrm{RWC}_{\mathrm{r}, 1}$ with $\varepsilon_{\text {leaf }}\left(r^{2}=0.32 ; p=0.002 ;\right.$ Fig. $\left.2 \mathrm{e}\right)$. These relationships imply that leaf capacitance increased with both decreasing WD and LMA, which was corroborated by independent datasets (Fig. 2f).

For bias-corrected sapwood PV traits (Fig. 3), we found that WD well-represented a single axis of variability along which $\pi_{\mathrm{o}, \mathrm{x}}, \varepsilon_{\mathrm{x}}$, and $R_{\mathrm{tlp}, \mathrm{x}}=1-\mathrm{RWC}_{\mathrm{tlp}, \mathrm{x}}$ were organized $\left(r^{2}=0.31\right.$ to 0.44$)$, with increasing WD leading to exponentially increasing $\varepsilon_{\mathrm{x}}$ and decreasing $\pi_{\mathrm{o}, \mathrm{x}}$ and $R_{\mathrm{tlp}, \mathrm{x}}$. The result was exponentially declining sapwood capacitance $\left(C_{\mathrm{ft}, \mathrm{x}}\right)$ with WD $\left(r^{2}=0.84\right.$; Fig. $\left.3 \mathrm{~d}\right)$. The same trends were gen- erally supported by the uncorrected data (Fig. S2.1), most importantly for $C_{\mathrm{ft}, \mathrm{x}}$.

On the full dataset of $P_{50, \mathrm{x}}$, we found a significant relationship with WD $(p<0.0001)$, but the explained variance was low $\left(r^{2}=0.08\right)$ due to a large number of high wood density species with high (less negative) $P_{50, \mathrm{x}}$ values. However, when limiting the dataset to measurements made using the bench DH, many values of high (less negative) $P_{50, \mathrm{x}}$ at intermediate to high WD were now excluded (the majority of which were obtained using the air injection method) and a stronger negative relationship emerged $\left(r^{2}=0.34\right)$ (Fig. 4a). In addition, we found that the slope $\left(a_{\mathrm{x}}\right)$ of the xylem FMC curve decreased significantly $(p<0.0001)$ with increasingly negative $P_{50, \mathrm{x}}$ (Fig. 4b), suggesting that threshold responses of embolism to increasing xylem tension were more pronounced in individuals with less resistant xylem.

The relationship of xylem efficiency on a leaf area basis $\left(k_{1, \max , \mathrm{x}}\right)$ with WD, while highly significant $(p<0.0001)$, explained only $7 \%$ of the variance (Fig. 5a). However, when examined in relation to reported values of light-saturated leaf photosynthesis rates $\left(A_{\max }\right)$, a greater fraction of the variance was explained $\left(r^{2}=0.29 ; p<0.0001\right)$ (Fig. $\left.5 b\right)$. Because $A_{\max }$ and WD were uncorrelated (Fig. 5d), we used them as independent predictors (as $A_{\max } / \mathrm{WD}$ ) of $k_{1, \max , \mathrm{x}}$, which now explained $42 \%$ of the variance (Fig. 5 c). Similar 

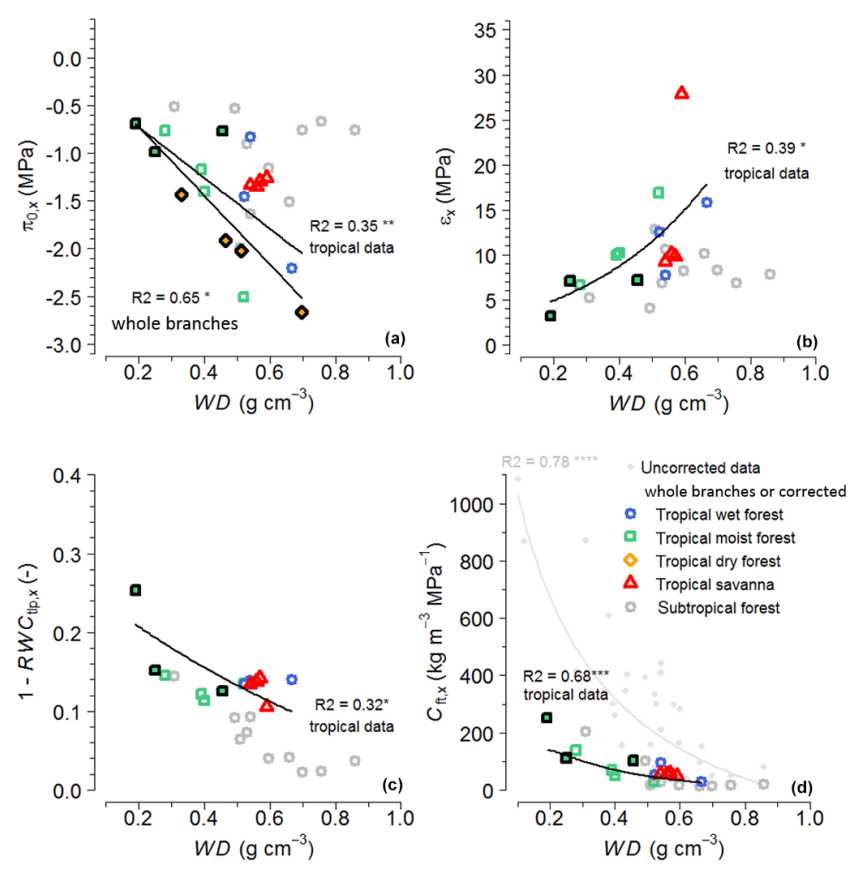

Figure 3. Tropical synthesis of sapwood PV parameters and resultant capacitance in relation to wood density (WD). (a) Osmotic potential at full turgor $\left(\pi_{\mathrm{O}, \mathrm{x}}\right)$, (b) bulk elastic modulus $\left(\varepsilon_{\mathrm{X}}\right)$, (c) relative water deficit at turgor loss $\left(R_{\mathrm{tlp}, \mathrm{x}}=1-\mathrm{RWC}_{\mathrm{tlp}, \mathrm{x}}\right)$, and (d) capacitance at full turgor $\left(C_{\mathrm{ft}, \mathrm{X}}\right)$. Sapwood PV curves conducted on trunk cores, and their associated parameters and capacitance are bias-corrected (see main text). Original data are shown in light gray in panel (d) and Supplement Fig. S2.1. Color scheme is given in the legend of panel (d). Asterisk codes for significance are the same as in Fig. 2.

trends were observed for xylem efficiency on a sapwood area basis ( $k_{\mathrm{s}, \text { max }, \mathrm{x}}$; Supplement Fig. S2.2).

While the Calvo-Alvarado et al. (2008) study showed no significant common relationship between $A_{1}: A_{\mathrm{S}}$ and $H$ or DBH across all individuals studied, it identified increasing $A_{1}: A_{\mathrm{s}}$ with $H$ within 4 out of 5 individuals (Fig. 6a). When we took species-averaged $A_{1}: A_{\mathrm{s}}$ from the CalvoAlvarado (2008) study and plotted the interspecific differences as a function of species-averaged LMA, the individuals largely fell on the same regression line as that of Patiño et al. (2012) (Fig. 6b). Therefore, it appears that for tropical forests leaf-level traits set the range of $A_{1}: A_{\mathrm{s}}$ by which variation occurs in response to height and/or light availability (Fig. 6c).

\subsubsection{Plant hydraulics parameterization}

Figure 7 shows the parameterization of all components of the plant hydraulics model (combining Table 2 and plant hydraulics model constitutive Eqs. 1-4) as a function of the TFS model input traits and tree height $(H)$. Figure $7 \mathrm{a}-\mathrm{c}$ demonstrate the distribution of leaf PV, sapwood PV, and xylem vul- nerability curves for a characteristic TFS model simulation in which each tree is assigned four trait values (WD, LMA, $\mathrm{N}_{\mathrm{L}}$, and $\mathrm{P}_{\mathrm{L}}$ ) according to the observed joint distribution (Taylor and Thompson 1986 resampling algorithm) of these four traits at the focal field site Caxiuana National Forest, which are used to parameterize each tree's constitutive equations (using Table 2), with each tree plotted as separate lines colored by trait values. This forest is representative of others in the region (Baraloto et al., 2010), showing decoupled leaf and stem economics (i.e., lack of any significant correlation between WD and any of the three leaf traits used as input for TFS). A consequence of this lack of leaf-stem trait coupling and our formulation of $k_{1, \max , \mathrm{x}}$ as empirically derived primarily from leaf traits (Fig. 5) while $P_{50, \mathrm{x}}$ derives from stem traits (Fig. 4a), the model input prescribes only a weak trade-off between $k_{1, \max , \mathrm{x}}$ and $P_{50, \mathrm{x}}$ (Fig. 7c), which is consistent with the data for this relationship (Fig. 8a). In contrast, Fig. 7d-f present "idealized" scenarios for a case in which leaf and stem economics are tightly coupled (specifically, between WD and LMA or WD and $A_{\max }$ ) over a wide range of input values. In this case, the consequence for the relationship between $k_{1, \max , \mathrm{x}}$ and $P_{50, \mathrm{x}}$ is a perfect trade-off (Fig. 7f). Finally, we represented the dual dependency of $A_{1}: A_{\mathrm{s}}$ on both LMA and tree size (Fig. 6) as an $A_{1}: A_{\mathrm{s}}-H$ relationship with an LMA-dependent slope (Fig. $7 \mathrm{~g}$ ). For a prescribed leaf biomass allometry function (as $\sim \mathrm{DBH}^{2} H$; Lescure et al., 1983), this $A_{1}: A_{\mathrm{s}}$ formulation predicted LMA as the driver of differences in sapwood area $\left(A_{\mathrm{S}}\right)-\mathrm{DBH}$ allometry, spanning the range of values given by our independent literature compilation across many different studies, though this relationship warrants further validation.

\subsubsection{Ability of hydraulics model parameterization to represent observed trade-offs and coordination among hydraulic traits}

Based on the pantropical xylem functional traits dataset, evidence for a trade-off between xylem efficiency (as $k_{\mathrm{s}, \max , \mathrm{x}}$ ) and safety $\left(P_{50, \mathrm{x}}\right)$ was insignificant $(p=0.14$ on $\log$ transformed data), which was also the case when limiting the database to the DH method ( $p=0.82$; Fig. 8a). However, when limiting the dataset to tropical dry forests (not savanna), a significant trade-off between xylem efficiency and safety emerged $\left(p<0.01 ; r^{2}=0.17\right)$, which was even stronger $\left(p<0.0001 ; r^{2}=0.44\right)$ when considering two tropical dry forest studies (see circled points in Fig. 8a; Markesteijn et al., 2011a, b; Mendez-Alonzo et al., 2012). Our plant hydraulics model parameterization is able to capture both the lack of a safety-efficiency trade-off, which occurs when stem and leaf economics are decoupled (Fig. 7c), and a strong safety-efficiency trade-off when stem and leaf economics are tightly coupled (Fig. 7f).

When we paired our sapwood PV data with data on xylem hydraulic safety, we found that $C_{\mathrm{ft}, \mathrm{x}}$ (xylem capacitance) and $P_{50, \mathrm{x}}$ demonstrated significant evidence $(p=0.02)$ for a 

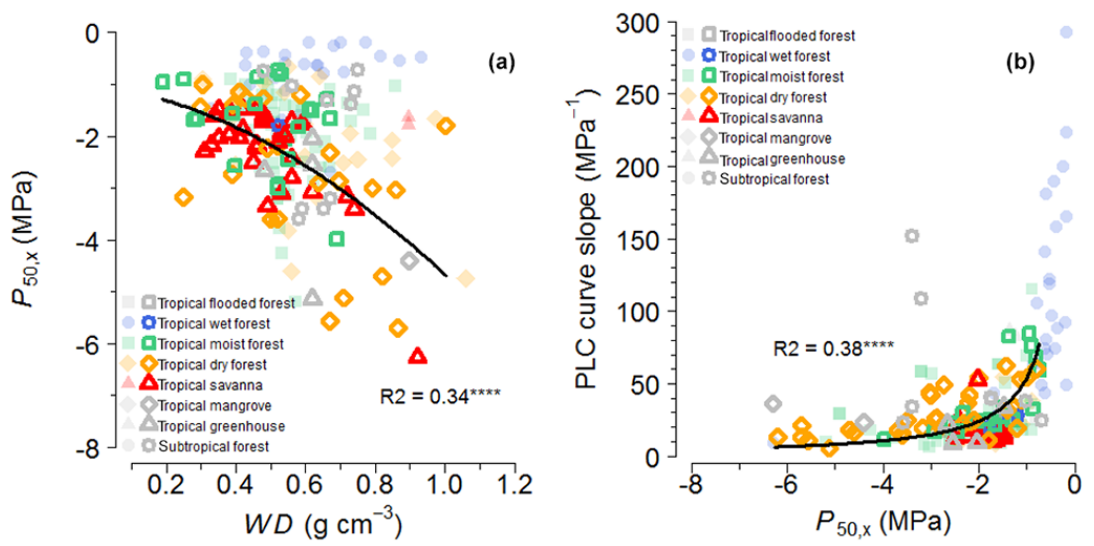

Figure 4. Tropical synthesis of xylem vulnerability. (a) Water potential at $50 \%$ loss of maximum xylem conductivity $\left(P_{50, x}\right)$. (b) Slope of percent loss of conductivity curve at $\left(P_{50, \mathrm{x}}\right)$ as a function of $P_{50, \mathrm{x}}$ : bold open symbols - bench dehydration method for $P_{50}$ measurement; light closed symbols - air injection + all other methods (see Sect. 3.1 in main text). Curves are fit through bench dehydration measurements conducted on field-derived plant material in upland tropical forests and savannas only (colored, bold open symbols). Asterisk codes for significance are the same as in Fig. 2.
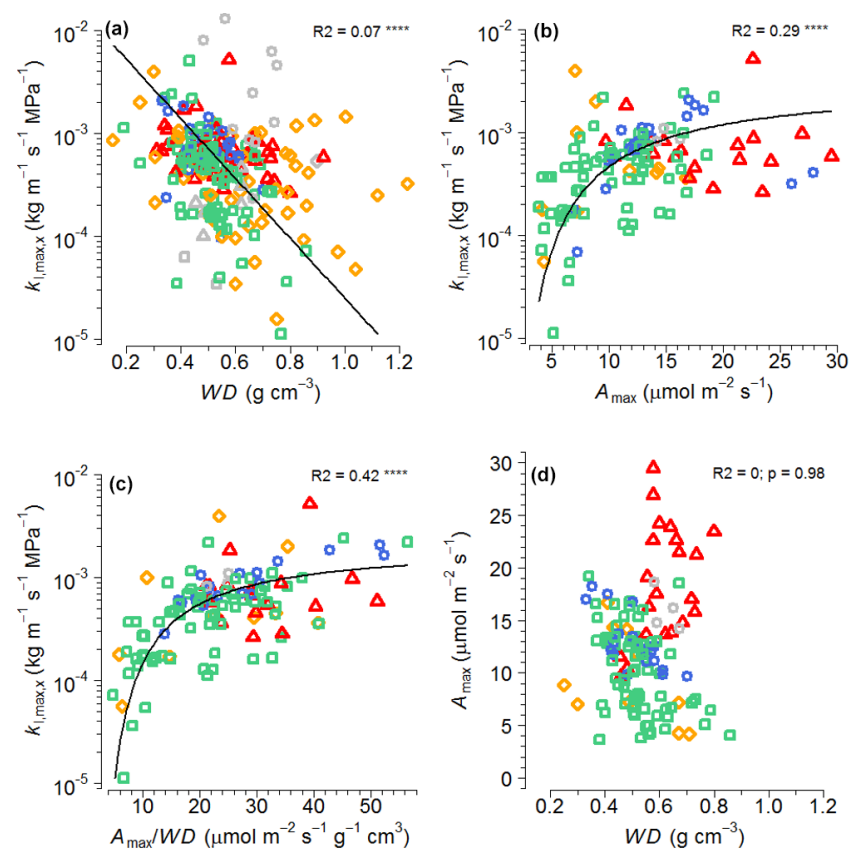

Figure 5. (a-c) Tropical synthesis of maximum xylem conductivity per unit leaf area $\left(k_{1, \max }\right)$ in relation to wood density (WD) and light-saturated photosynthesis rate $\left(A_{\max }\right)$. (d) No significant correlation between $A_{\max }$ and WD exists in this dataset, justifying their use as independent simultaneous predictors of $k_{1, \max }$. Symbols as in Figs. 2-3. See Supplement Fig. S2.2 for a version of this figure in terms of $k_{\mathrm{s}, \max }$. Asterisk codes for significance are the same as in Fig. 2. trade-off in drought avoidance (increasing capacitance) and drought tolerance (increasingly negative $P_{50, \mathrm{x}}$ ) (Fig. $8 \mathrm{~b}$ ). The strength of this relationship became marginally insignificant ( $p=0.05$ ) when considering $P_{50, \mathrm{x}}$ values obtained with the DH method only, but was unaffected by the correction factor that we applied to the sapwood PV curves, remaining significant $(p=0.02$ and $p=0.01$ for all data and DHlimited data, respectively; Supplement Fig. S2.4). Because $C_{\mathrm{ft}, \mathrm{x}}$ and $P_{50, \mathrm{x}}$ both derive directly from WD, our plant hydraulics model parameterization also follows this avoidancetolerance trade-off (cf. thin line Fig. 8b).

Finally, joining of the leaf PV database with the xylem functional traits database demonstrated significant evidence in support of coordination between leaf and xylem drought tolerance, as given by significant relationships between leaf drought tolerance traits $\pi_{\mathrm{o}, 1}$ and associated turgor loss point $\pi_{\text {tlp, } 1}$ with xylem drought tolerance traits $P_{50, \mathrm{x}}$ and $P_{88, \mathrm{x}}$, albeit with $R^{2}$ values no greater than 0.3 (Fig. $8 \mathrm{c}-\mathrm{f}$ ). This cross-tissue coordination is also preserved by our model parameterization, with WD driving most of the variation in this coordination space and LMA generating residual variation in leaf drought tolerance (thin lines, Fig. 8c-f).

\subsection{Model experiments}

\subsubsection{Impact of plant hydraulics on size and light dependency of transpiration}

Figure 9 shows how mean \pm 1 SD diurnal cycles of transpiration change as a function of canopy position and wet/dry season for both TFS v.1 and TFS v.1-Hydro. The large increase in simulated transpiration in the dry season for both TFS v.1 and TFS v.1-Hydro (Fig. 9e-f) is driven by the comparatively large increase in incoming solar radiation, and hence absorbed radiation, due to a reduction in cloud cover 

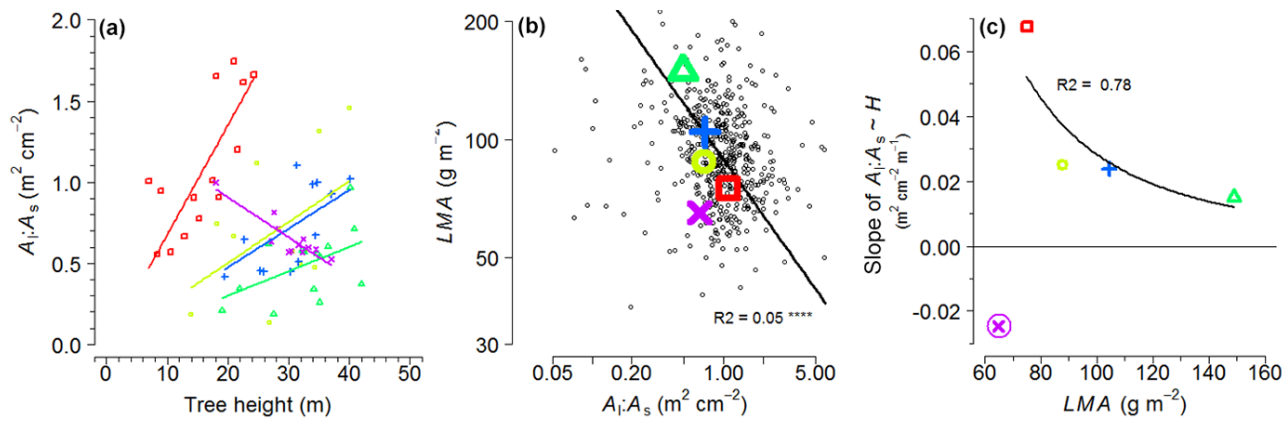

Figure 6. Tropical synthesis showing the dual dependency of the leaf : sapwood area ratio $\left(A_{1}: A_{\mathrm{S}}\right)$ on both leaf mass per area (LMA) and tree height $(H)$. (a) $A_{1}: A_{\mathrm{S}}$ vs. tree height, replotted from Calvo-Alvarado et al. (2008). (b) Species-averaged LMA vs. $A_{1}: A_{\mathrm{S}}$ from panel (a) overlain on a much broader dataset from the Amazon basin (replotted from Patiño et al., 2012). (c) The slope of the $A_{1}: A_{\mathrm{s}}-H$ relationship in panel (a) vs. LMA. Circled datapoint is Pentaclethra macroloba, a compound-leaf species averaging 1600 leaflets/leaf and is excluded from the regression. The dependency of $A_{1}: A_{\mathrm{S}}$ on LMA in panel (b) is thus implemented in the model via variations in the slope of $A_{1}: A_{\mathrm{S}}$ with $H$ in panel (c); see Fig. 7g. Asterisk codes for significance are the same as in Fig. 2.
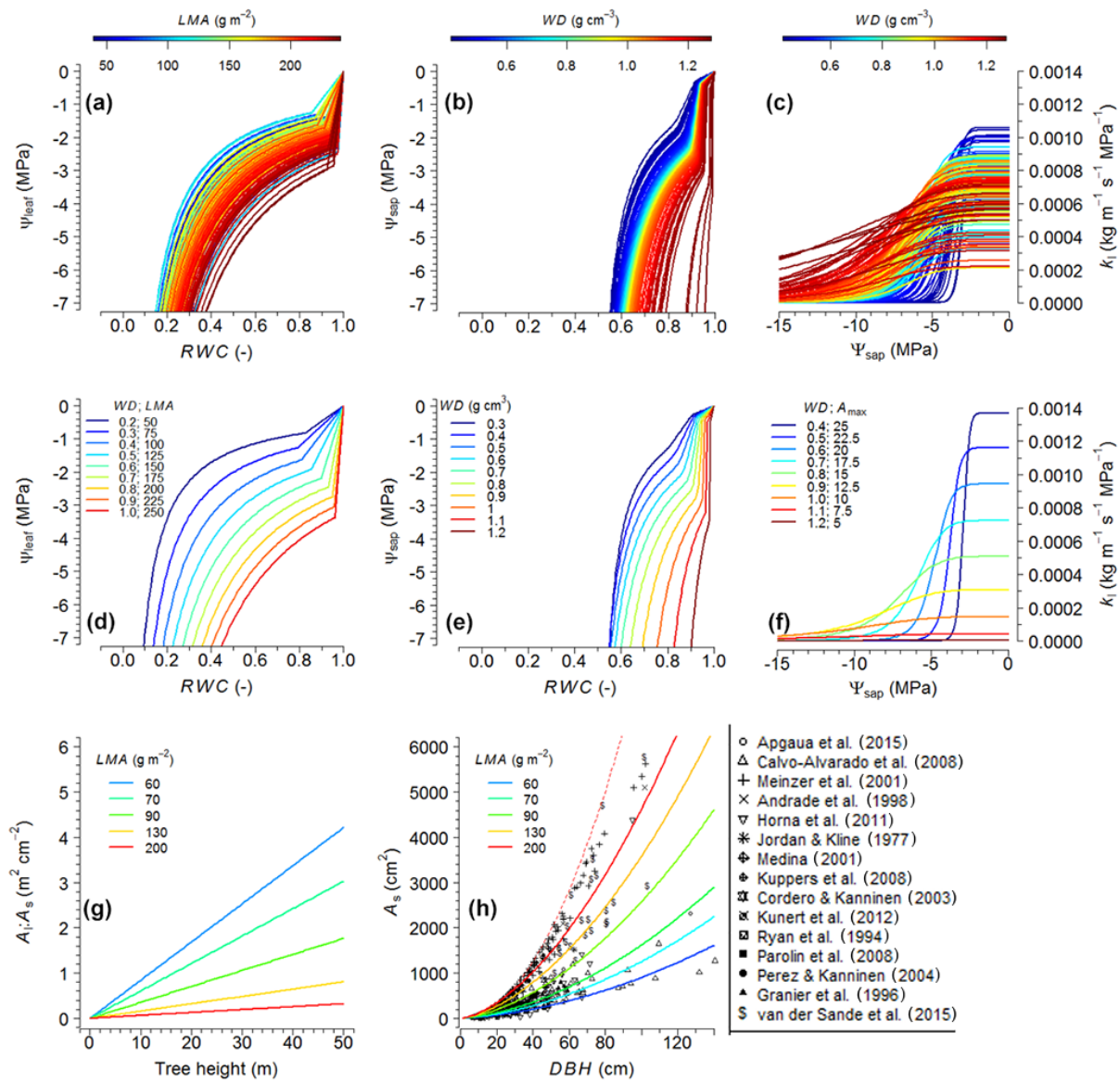

Apgava etal (2015)

$\triangle$ Calvo-Alvarado et al. (2008)

+ Meinzer et al. (2001)

$\times$ Andrade et al. (1998)

v Horna et al. (2011)

* Jordan \& Kline (1977)

- Medina (2001)

Kuppers et al. (2008)

ax Cordero \& Kanninen (2003)

Kunert et al. (2012)

ॠ Ryan et al. (1994)

- Parolin et al. (2008)

- Perez \& Kanninen (2004)

S van der Sande et al. (2015)

Figure 7. Plant hydraulics model parameterization as a function of plant traits leaf mass per area (LMA), wood density (WD), light-saturated photosynthesis rate $\left(A_{\max }\right)$, and size $(H)$ resulting from the syntheses presented in Figs. 2-6 and summarized in Table 2. (a, b) Leaf and sapwood PV curves, respectively (Eqs. 1-3), which relate tissue water potential to relative water content (RWC). (c) Sapwood xylem vulnerability curves $\left(\mathrm{FMC}_{\mathrm{X}}\right.$; Eq. 4) multiplied by maximum leaf-specific xylem conductivity based on a dataset of the joint distribution of WD and $A_{\max }$ in an eastern Amazonian forest. Note that curves in panels (a) and (c) are also dependent on WD and $A_{\text {max }}$, respectively, in addition to the color scale shown. Panels (d-f) same as panels (a-c) except for an idealized distribution of plant traits in which trait variation occurs over a single axis (LMA $\left.\sim \mathrm{WD} \sim A_{\max }\right)$. (g) Leaf : sapwood area ratio $\left(A_{1}: A_{\mathrm{S}}\right)$ as a function of LMA and tree height. (h) Sapwood area $\left(A_{\mathrm{S}}\right)$ as a function of DBH and LMA, overlain with synthesis of independent measurements of $A_{\mathrm{S}}$. Dashed red line in panel (h) represents theoretical maximum for $A_{\mathrm{S}}$ (entirely sapwood). 


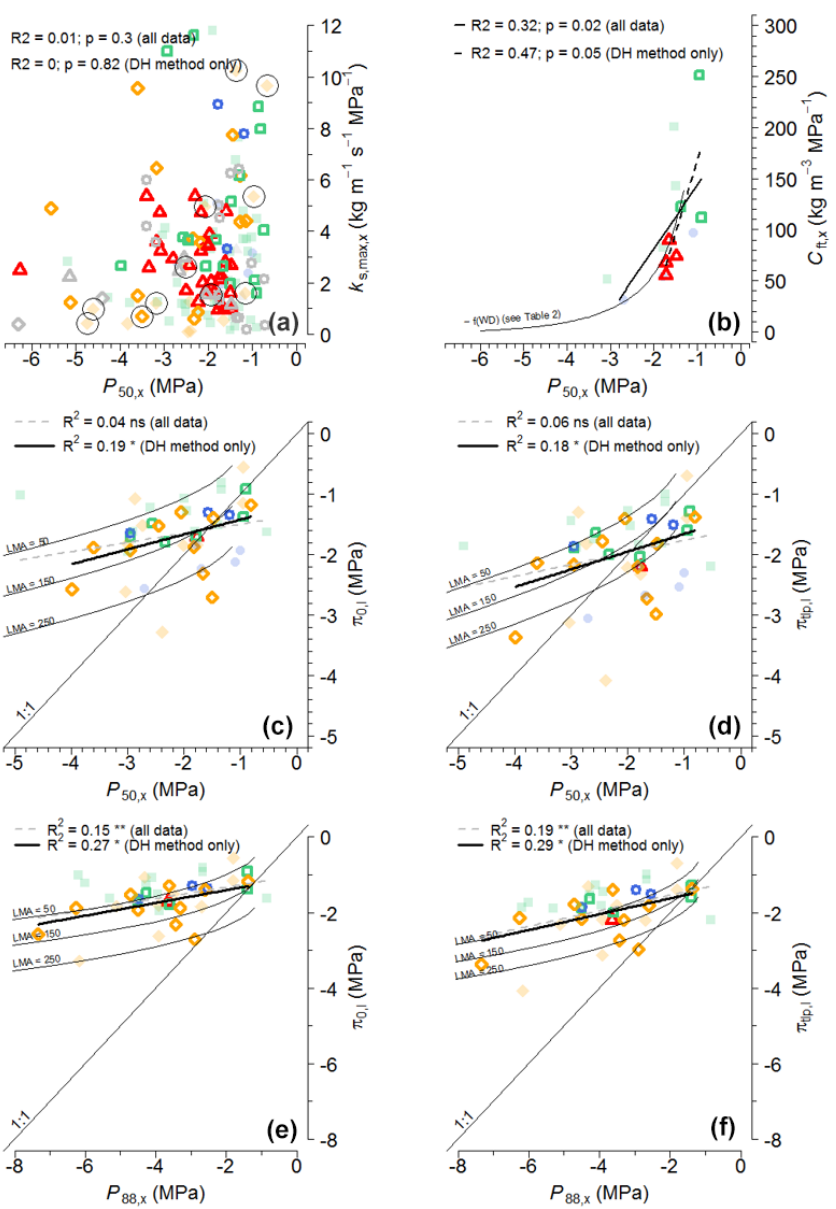

Figure 8. Tropical synthesis of trade-offs or coordination of various hydraulic traits with the water potential at 50 or $88 \%$ loss of maximum xylem conductivity $\left(P_{50, \mathrm{x}}\right.$ or $\left.P_{88, \mathrm{x}}\right)$. (a) The relationship between maximum xylem conductivity $\left(k_{\mathrm{s}, \max , \mathrm{x}}\right)$ and $P_{50, \mathrm{x}}$ does not support the notion of a trade-off between xylem efficiency and safety, except in tropical dry forests (circled points). (b) The relationship between xylem capacitance $\left(C_{\mathrm{ft}}\right)$ and $P_{50}$ provides tentative evidence for a trade-off between drought avoidance and tolerance. (c-f) Relationships of the leaf osmotic potential at full turgor $\left(\pi_{\mathrm{o}, 1}\right)$ and the leaf turgor loss point $\left(\pi_{\mathrm{tl}, 1}\right)$ with $P_{88, \mathrm{x}}$ support the hypothesis of coordination between leaf and xylem drought resistance, with less support for the hypothesis in terms of $P_{50, \mathrm{x}}$. Thin lines in panels (b-f) correspond to the empirical equations in Table 2 over a wide range of input WD [0.2, 1.2] and LMA [50, 250]. Symbols are the same as in Fig. 4. See Supplement Fig. S2.3 for a version of panel (b) in which no correction factor was applied to sapwood PV curves. Asterisk codes for significance are the same as in Fig. 2.

(Fig. 9a-d) (Carswell, 2002; Fisher et al., 2007). At the level of individual tree crowns, canopy position is the dominant control over the amount of absorbed PAR (compare different colored lines in Fig. 9a-d). These trends remain when considering total tree transpiration (Fig. 9i, j, k, l), but variation in crown size adds significant variability in total water fluxes, especially for canopy trees (very small trees can still be in the canopy depending on subplot assignment). The effect of including plant hydraulics in TFS v.1-Hydro was to limit late morning and afternoon transpiration via the depletion of stored water within the canopy and tree stem, which caused midday declines in leaf water potential (see Fig. 10) and induced hydraulic limitation to water flux via the $\mathrm{FMC}_{\mathrm{gs}}$ term (see Eq. 8). Hydraulic limitation was highest in canopy trees, intermediate in subcanopy trees, and nonexistent in understory trees, but this limitation only occurred during the dry season when incoming radiation was sufficiently high to drive high potential evapotranspiration (compare the effect of including hydraulics in Fig. 9e and g vs. Fig. 9f and h), consistent with other studies (McDowell et al., 2005).

\subsubsection{Impact of plant hydraulics on the trait dependency of transpiration}

Figure 10 shows how mean \pm 1 SE diurnal cycles of transpiration per unit crown area of three large (50-55 cm DBH and 26-27 m height) individuals change as a function of a single plant trait $\left(\mathrm{P}_{\mathrm{L}}, \mathrm{WD}\right.$, or LMA) and wet/dry season for both TFS v.1 and TFS v.1-Hydro. In most cases, the seasonal wet to dry increase in transpiration associated with incoming radiation is the same as for the previous model experiment. In the absence of plant hydraulics, leaf nutrients drive large differences in photosynthetic parameters and rates, which, by model design, then drive large differences in $g_{\mathrm{s}, \max }$ and transpiration rates (Fig. 10a, b). Because our plant hydraulic trait parameterization explicitly links hydraulic transport rates $\left(k_{\mathrm{s}, \max , \mathrm{x}}\right)$ to photosynthetic capacity, this trend is preserved in TFS v.1-Hydro, except that all trees experience hydraulic limitation (Fig. 10c, d). In contrast, large canopy trees with differences in WD and LMA in default TFS simulations demonstrated no differences in simulated transpiration dynamics (Fig. 10e, f). In the case of WD, adding plant hydraulics caused hydraulic limitation across all three individuals but surprisingly little to no divergence in simulated dynamics (Fig. 10g, h), despite large differences in plant hydraulic traits, which derive from WD (Table 2). This lack of a difference arises, however, because the effects of decreasing WD have opposing effects on midday leaf water potential via sapwood capacitance and xylem $P_{50}$ because of the drought avoidance-tolerance trade-off (Fig. 8b). In the case of LMA, dramatic differences emerged among the three individuals with differing LMAs (209, 95 and $\left.47 \mathrm{~g} \mathrm{~m}^{-2}\right)$ upon the inclusion of plant hydraulics (Fig. 10k, 1). This was driven by large differences in total tree aboveground hydraulic conductance $\left(K_{\text {max,tree,ag }}\right)$, which arose because of large differences in $A_{1}: A_{\mathrm{s}}$ that ranged from $0.1-1.8 \mathrm{~m}^{2} \mathrm{~cm}^{-2}$ (itself arising from the LMA differences; see Fig. $7 \mathrm{~g}$, $\mathrm{h}$ and Table 2). By Darcy's law, a reduction in conductance results in a comparative reduction in water flux for a given water potential gradient. 


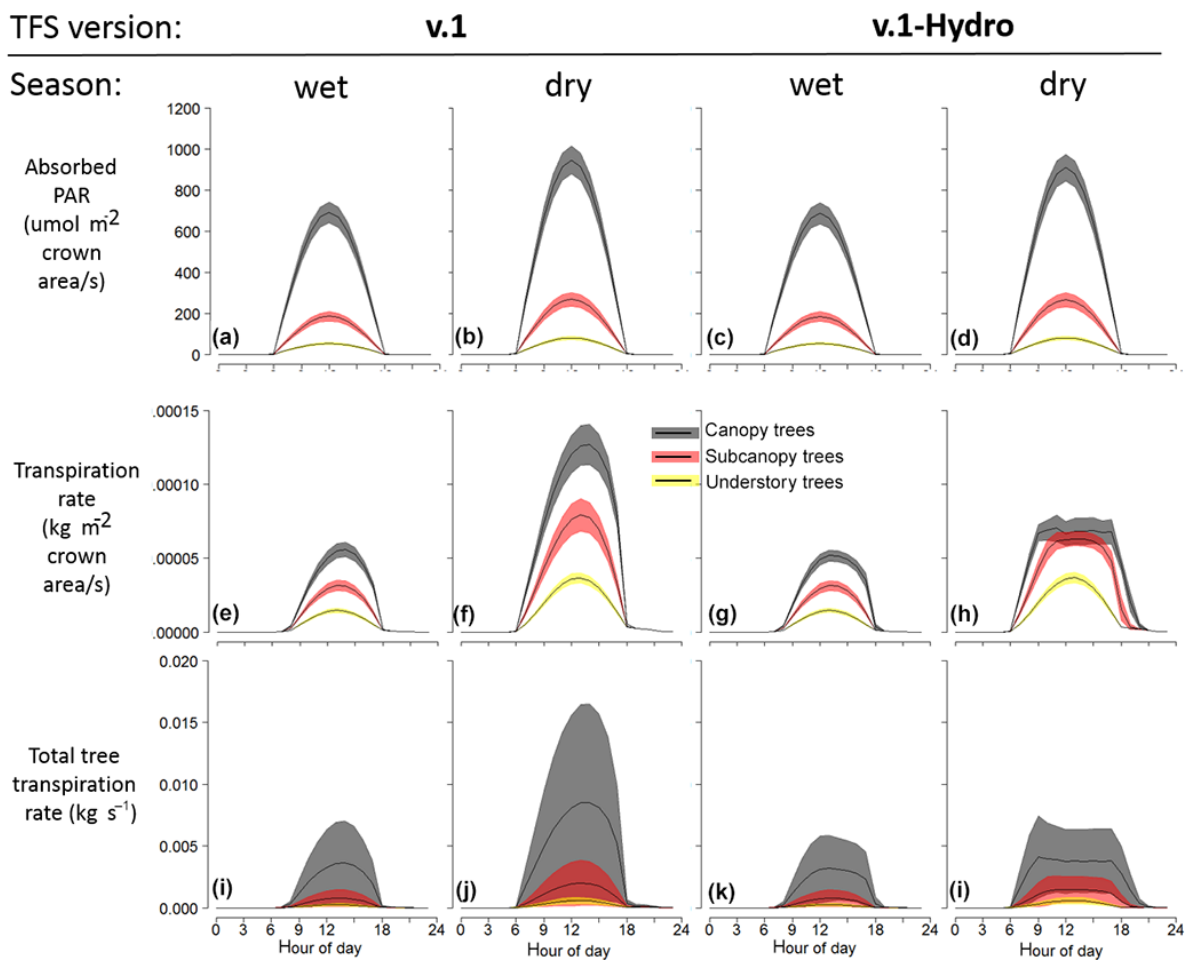

Figure 9. TFS simulated mean ( $\pm 1 \mathrm{SD}$ ) diurnal cycles across all individuals by canopy position, in wet and dry seasons with (v.1-Hydro) and without (v.1) plant hydraulics implemented, at Caxiuana, Brazil. (a-d) Total absorbed photosynthetically active radiation, (e-h) transpiration rate per unit crown area, $(\mathbf{i}-\mathbf{l})$ total tree transpiration rate.

\subsection{Model evaluation}

TFS v.1-Hydro demonstrated a capability to represent lags in water flux throughout the leaf-stem-soil continuum (Fig. S3.1), with sap flux lagging leaf-level transpiration, and root uptake continuing into the nighttime hours, which is consistent with the diurnal dynamics of soil moisture shown in other ecosystems. In addition, as expected, the model predicted that soil most adjacent to absorbing roots experiences significantly lower rates of volumetric root water uptake as compared to more distal rhizosphere shells (Fig. S3.2), demonstrating the capability for the model to represent rhizosphere hydraulic limitation if soil gets sufficiently dry.

\subsubsection{Diurnal dynamics of leaf and stem water potential}

Observed diurnal dynamics of leaf and stem water potential ( $\psi_{\text {leaf }}$ and $\psi_{\text {stem }}$, respectively) indicated, for all trees regardless of size, predawn $(\sim 06: 00 \mathrm{am})$ values in the range of -0.1 to $-0.4 \mathrm{MPa}$, whereas midday water potentials varied largely in concert with tree size (Fig. 11). The model captured the observed diurnal trends in both $\psi_{\text {leaf }}$ and $\psi_{\text {stem }}$ reasonably well, especially given the absence of any model tuning or tissue-level hydraulic trait differences among individuals. This suggests that the first-order control over the variation in $\psi_{\text {leaf }}$ among individuals was primarily due to the variation in radiation interception (both across seasons and within the canopy) and tree size, rather than tissue-level hydraulic traits. See Fig. S3.4 for an alternate version of Fig. 11 showing how root water potentials vary diurnally for these individuals.

Despite large (upwards of $-4 \mathrm{MPa}$ ) differences in midday and predawn leaf values, observed $\psi_{\text {stem }}$ remained for the most part within $-1 \mathrm{MPa}$ of the observed $\psi_{\text {leaf }}$ values (Fig. 11). For the larger trees, observed midday $\psi_{\text {stem }}$ during the dry season was in the range of -2 to $-3 \mathrm{MPa}$. In contrast, modeled $\psi_{\text {stem }}$ rarely went more negative than $-1 \mathrm{MPa}$, suggesting that the model parameterization overestimates sapwood capacitance $\left(C_{\mathrm{ft}, \mathrm{x}}\right)$.

\subsubsection{Impact of model parameterization on fidelity of simulated midday leaf water potential}

Modeled dynamics of leaf water potential at the Caxiuana site captured observed variation at both diurnal and seasonal timescales (Supplement Fig. S2.6). Throughout each day, reductions in leaf water potential lagged that of the stem and transporting root system, congruent with the buffering role of canopy and stem capacitance, with refilling of distal tissues occurring at night (results not shown). The model also simulated reductions in predawn leaf water potential in the dry 


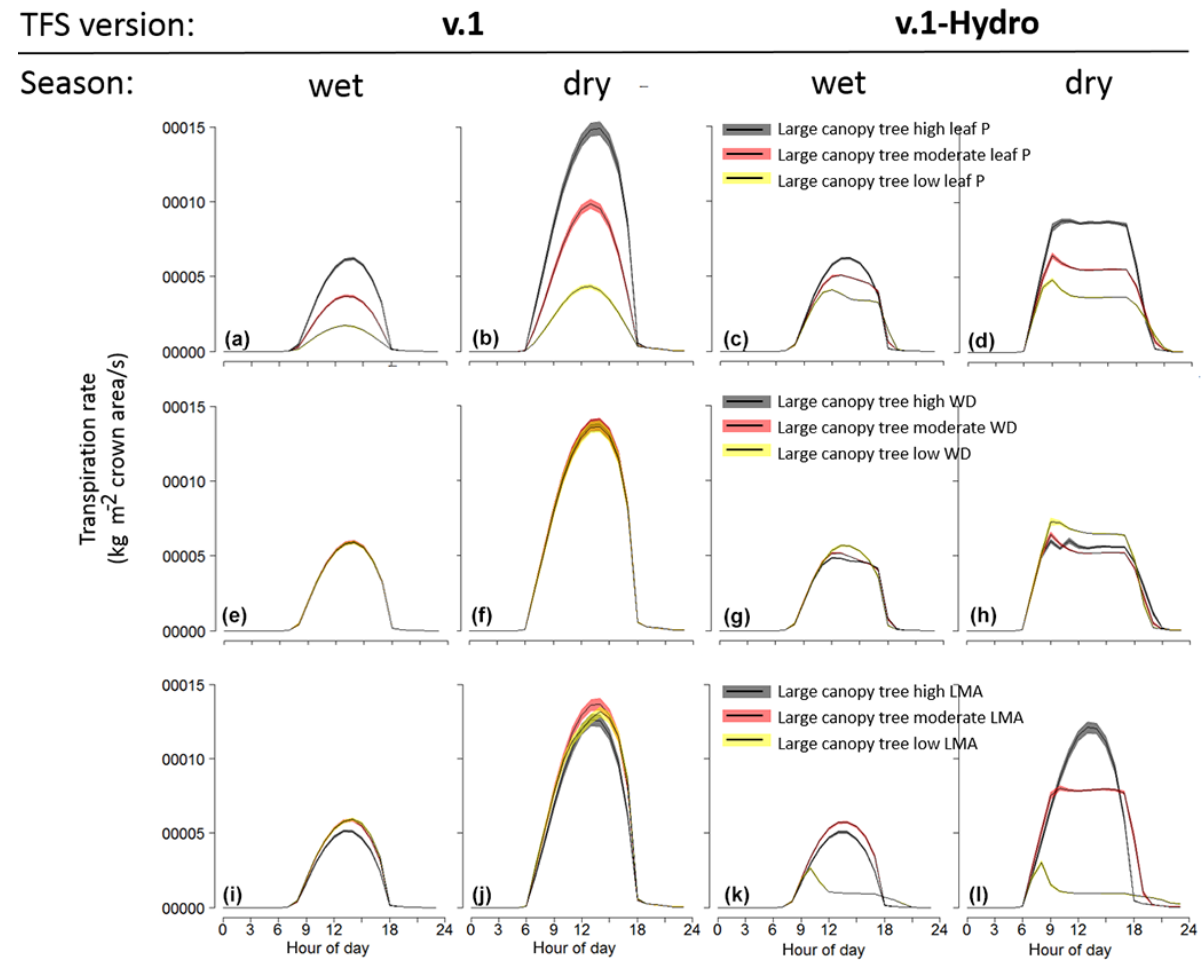

Figure 10. TFS simulated mean ( $\pm 1 \mathrm{SE})$ diurnal cycles of transpiration of three large $(50-55 \mathrm{~cm} \mathrm{DBH})$ individual trees receiving full sunlight but differing in one plant trait, stratified by wet/dry season and TFS version with (v.1-Hydro) and without (v.1) plant hydraulics implemented, at Caxiuana, Brazil. (a-d) Individuals differing in leaf $P$ exhibit different light-saturated photosynthesis rates $\left(A_{\max }\right)$ and consequently $\mathrm{g}_{\mathrm{s}, \max }$ and, in v.1-Hydro, $k_{\mathrm{s}, \max }$. (e-h) Individuals differing in wood density WD exhibit no difference in maximum transpiration rate per unit crown area in v.1, but different rates in v.1-Hydro emerge due to differences in xylem safety $\left(P_{50, \mathrm{x}}\right)$ and, hence, stomatal control $\left(P_{50, \mathrm{gs}}\right)$. (i-l) Individuals differing in leaf mass per area LMA exhibit little difference in v.1 but large differences in v.1-Hydro, due to large differences in the leaf : sapwood area ratio $\left(A_{1}: A_{\mathrm{s}}\right)$ and, hence, total aboveground conductance $\left(K_{\max , a g}\right)$.

Table 3. Properties of simulated and observed trees given in Fig. 11.

\begin{tabular}{llrrrrr}
\hline $\begin{array}{l}\text { Figure 11 } \\
\text { panels }\end{array}$ & $\begin{array}{l}\text { Tree } \\
\mathrm{ID}^{\mathrm{a}}\end{array}$ & $\begin{array}{r}\text { Observed } \\
\text { DBH }(\mathrm{cm})\end{array}$ & $\begin{array}{r}\text { Simulated } \\
\text { DBH }(\mathrm{cm})\end{array}$ & $\begin{array}{r}\text { Simulated } \\
\text { canopy layer }\end{array}$ & $\begin{array}{r}\text { Simulated } A_{1}: A_{\mathrm{s}} \\
\left(\mathrm{m}^{2} \mathrm{~cm}^{-2}\right)\end{array}$ & $\begin{array}{r}\text { Simulated } K_{\max , \mathrm{ag}} \\
\left(\mathrm{kg} \mathrm{s}^{-1} \mathrm{MPa}^{-1}\right)\end{array}$ \\
\hline $\mathrm{a}, \mathrm{b}$ & $\mathrm{C} 1$ & 15.6 & 15.6 & 2 & 0.41 & 0.062 \\
c, d & $\mathrm{C} 2$ & 18.7 & $18.8^{\mathrm{b}}$ & 2,3 & $0.45^{\mathrm{b}}$ & $0.064^{\mathrm{b}}$ \\
e, f & $\mathrm{C} 4$ & 43.9 & $43.9^{\mathrm{b}}$ & 1,2 & $0.74^{\mathrm{b}}$ & $0.076^{\mathrm{b}}$ \\
$\mathrm{g}, \mathrm{h}$ & $\mathrm{C} 3$ & 51.4 & 51.4 & 2 & 0.81 & 0.078 \\
\hline
\end{tabular}

${ }^{a}$ As given in Fisher et al. (2006). ${ }^{b}$ Two simulated trees were included in this size class. Value given is the average of the two trees.

season due to reductions in soil water supply, and captured an increasing magnitude of diurnal variation driven largely by light-driven increases in canopy transpiration rates typical of equatorial Amazonian dry seasons (Fig. S6) (Carswell, 2002; Fisher et al., 2007; Hasler and Avissar, 2007; da Rocha et al., 2009; Christoffersen et al., 2014).

Each of three successive model parameterization adjustments was able to make incremental improvements in the fidelity of modeled $\psi_{\text {leaf }}$, and these adjustments are informative for understanding the dominant controls over individuallevel differences in $\psi_{\text {leaf }}$. First, when the model's treatment of xylem conduit taper is turned off, the model in most cases overestimated the negative hydraulic impacts of tree height, with modeled midday $\psi_{\text {leaf }}$ falling below that which was observed (Fig. 12a). Re-instating xylem taper ameliorated the negative effects of tree height for some trees by increasing $K_{\text {max,tree,ag }}$ and thus reducing the soil-leaf water potential gradient needed to maintain transpiration (Fig. 12b). Next, adjusting the canopy position of two of the four individual trees from a subcanopy (canopy layer is 2) light environment to an understory (canopy layer is 3 ) light environment reduced the incoming radiation for these trees and hence their 


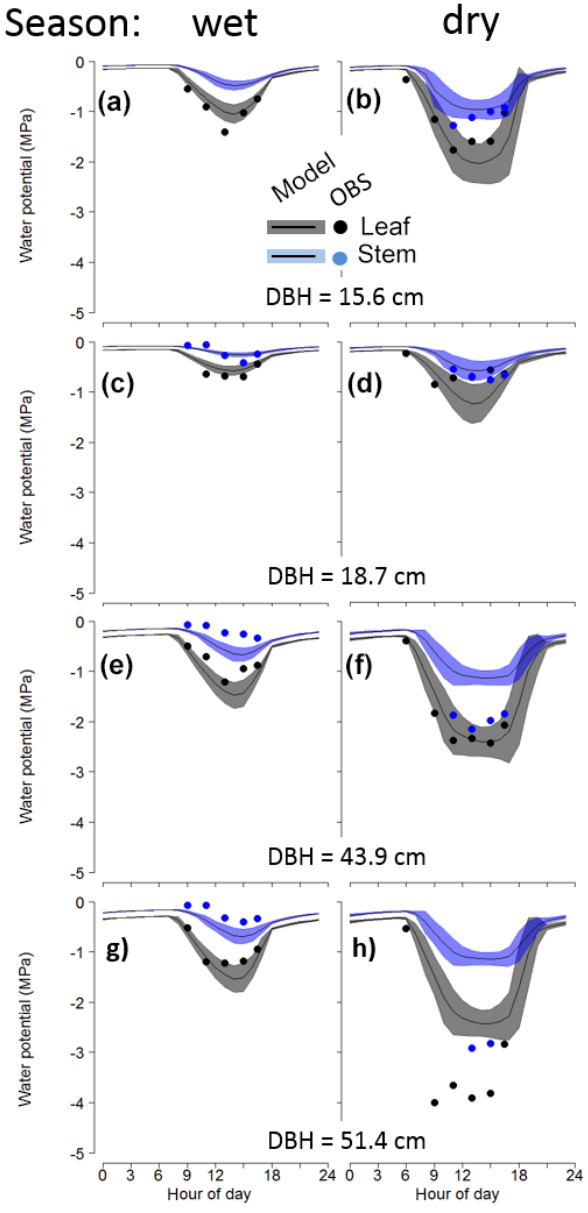

Figure 11. TFS v.1-Hydro simulated and observed diurnal variation in leaf and stem water potential for individual trees subject to seasonal variation in water availability at Caxiuana National Forest, Brazil. Simulated trees possess identical trait values equal to the plot mean and were matched with observed trees based on size (DBH) (see Table 3). Trees are in order from smallest to largest, top to bottom, and are the following trees given in Fisher et al. (2006): (a-b) tree C1, (c-d) tree C2, and (e-f) tree C4.

transpiration rates and midday $\psi_{\text {leaf }}$ values (Fig. 12c). Finally, we found that the extremely negative midday $\psi_{\text {leaf }}$ values during the dry season of the largest tree (tree $\mathrm{C} 3$ of Fisher et al., 2006) could be better simulated by allowing its stomatal regulation to behave in a more anisohydric way (less stomatal regulation of leaf water potential) by setting its $P_{50, \mathrm{gs}}=-5.0 \mathrm{MPa}$.

\subsubsection{Fidelity of modeled stand-level transpiration}

Without plant hydraulics, TFS v.1 had a large positive bias in simulated dry season stand-level transpiration rates (Fig. 13a, b). Including plant hydraulics (TFS v.1-Hydro) largely eliminated this dry season positive bias when plot-mean trait values were used (Fig. 13a). However, TFS v.1-Hydro tended to underestimate observed transpiration year-round when each

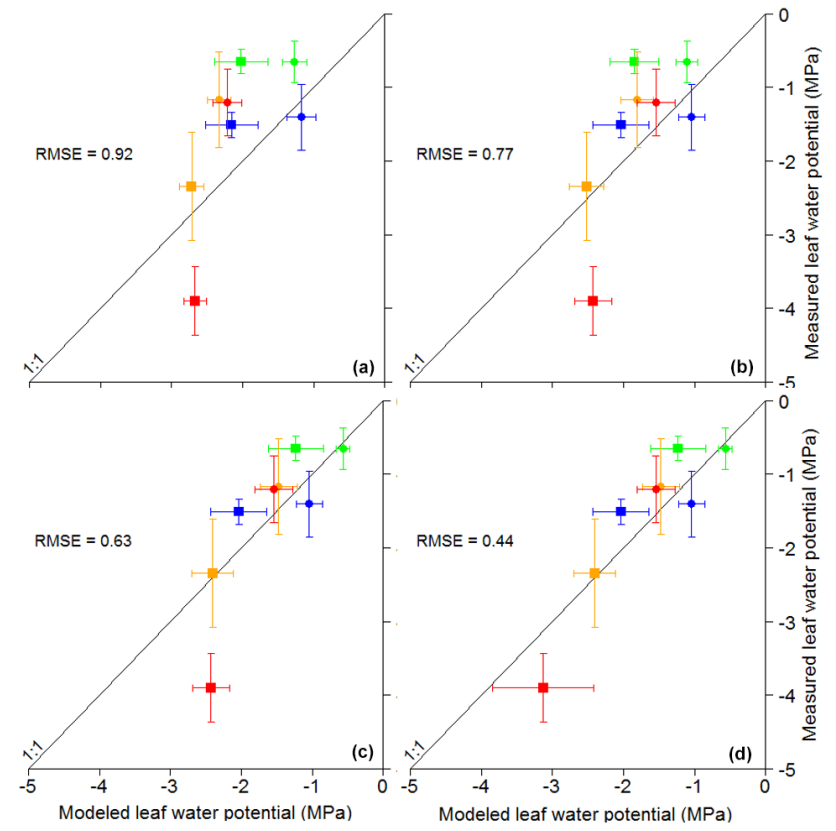

Figure 12. Simulated vs. observed individual-level variation in midday leaf water potential, Caxiuana National Forest, Brazil. (a) Without accounting for xylem taper and using mean plot values for input plant traits and derived hydraulic traits from Table 2 (Savage et al., 2010, taper exponent $p=0.0, \mathrm{LMA}=96.1 \mathrm{~g} \mathrm{~m}^{-2}$, $\mathrm{WD}=0.73 \mathrm{~g} \mathrm{~cm}^{-3}, \mathrm{~N}_{\mathrm{L}}=20.9 \mathrm{mg} \mathrm{g}^{-1}, \mathrm{P}_{\mathrm{L}}=0.59 \mathrm{mg} \mathrm{g}^{-1}$ ). (b) As in panel (a) but accounting for xylem taper $(p=1 / 3)$. (c) As in panel (b) but after modifying canopy position of individual trees (see Methods). Panel (d) as in panel (c) but forcing tree C3 to be less isohydric by setting $P_{50, \mathrm{gs}}=-5.0 \mathrm{MPa}\left(P_{50, \mathrm{x}}\right.$ remained the same at $-3.2 \mathrm{MPa}$ ). Different colors represent the following four individuals from Fisher et al. (2006): green - tree C2 (18.7 cm DBH), blue - tree C1 $(15.6 \mathrm{~cm} \mathrm{DBH})$, orange - tree C4 $(43.9 \mathrm{~cm} \mathrm{DBH})$, and red - tree C3 $(51.5 \mathrm{~cm} \mathrm{DBH})$. Filled circles and squares represent wet and dry season values, respectively.

tree was assigned different trait values (Fig. 13b) according to the observed plot distribution (according to Fig. $7 \mathrm{a}-\mathrm{c}$ ).

\section{Discussion}

We present here a plant hydraulics model built from the bottom-up. By "bottom-up" we mean that this model is parameterized at the level of plant tissues (leaf, stem, roots) and then scaled to the whole-tree level using established theory about how size and aboveground-branching structures impact whole-tree function. We embedded this model within a size-structured forest simulator (TFS) providing critical input information to the plant hydraulics model on light environments of individual trees and community-level size and trait distributions (collectively these two models comprise TFS v.1-Hydro), but the plant hydraulics scheme is appropriate for inclusion within any demographic dynamic vegetation model. Our plant hydraulics model is also trait driven. 


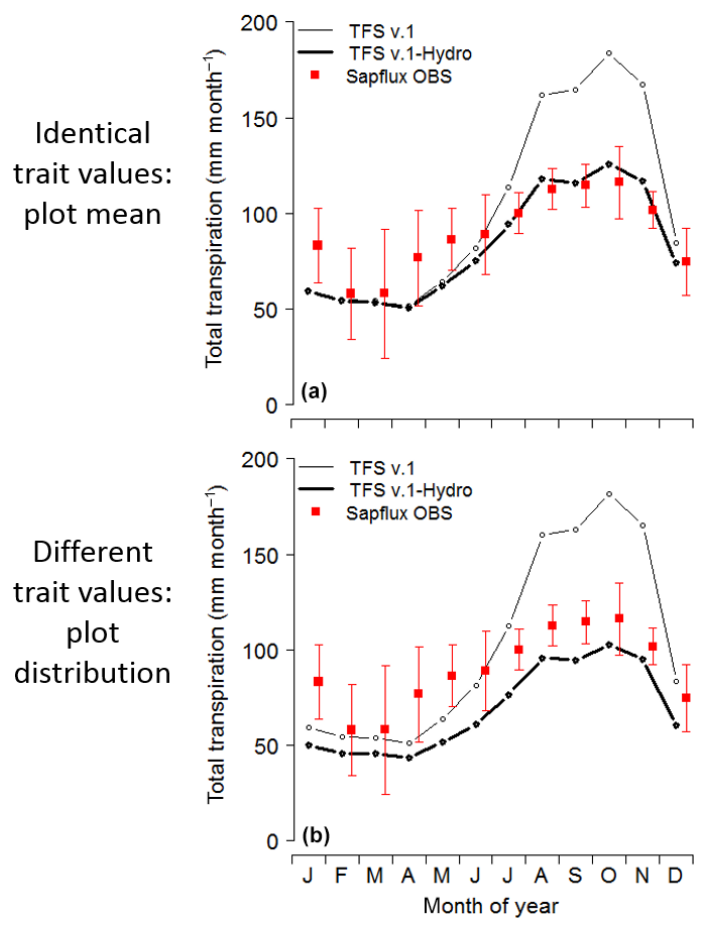

Figure 13. Simulated and observed stand-level total transpiration at Caxiuana National Forest, Brazil. Model simulations were carried out where individuals were either (a) forced to take on identical plot-mean trait values (LMA $=96.1 \mathrm{~g} \mathrm{~m}^{-2}, \mathrm{WD}=0.73 \mathrm{~g} \mathrm{~cm}^{-3}$, $\mathrm{N}_{\mathrm{L}}=20.9 \mathrm{mg} \mathrm{g}^{-1}, \mathrm{P}_{\mathrm{L}}=0.59 \mathrm{mg} \mathrm{g}^{-1}$ ), or (b) allowed to vary according to the plot-level trait distribution.

By "trait driven" we mean that individual trees take on distinct plant functional trait values (WD, LMA, $\mathrm{N}_{\mathrm{L}}, \mathrm{P}_{\mathrm{L}}$ ) according to observed plot-level trait distributions and we have parameterized hydraulic traits from each tree's assigned traits according to a pantropical empirical synthesis. Our empirical synthesis documented widespread correlations between plant hydraulic traits and the leaf and stem economic traits used in our model (Figs. 2-6), and we additionally showed that even where such correlations were weak, the hydraulic trait parameterization for our model respected observed ecological trade-offs and coordination among hydraulic traits (Figs. 7-8) known to be crucial to plant water use and survival. This provides encouragement to the growing research agenda to expand the role of plant functional traits in parameterizing Earth system models (ESMs) (Fisher et al., 2015; Sakschewski et al., 2015). The model also reasonably captures size- and light-related interindividual variation in water potential across individuals (Figs. 11-12) without need for significant model tuning. Finally, the model makes substantial improvements to TFS v.1 in terms of simulated transpiration rates (Fig. 13a, b), highlighting how plant hydraulics mediate the biosphere-atmosphere exchange of carbon and water. In conclusion, TFS v.1-Hydro represents a key and advanced model capability to represent differential performance of individual trees based on hydraulic traits, size and light environments (Figs. 9-10). Future work coupling the present scheme with community dynamics (mortality, growth and recruitment) has the potential to predict shifts in community trait distributions under changing moisture regimes, as has been observed or implied in studies of tropical forest species distributions and community dynamics (Engelbrecht et al., 2007; Fauset et al., 2012).

\subsection{Underlying causes and implications of trait-trait relationships}

The relationship of leaf $\pi_{0,1}$ (i.e., cell "saltiness") with WD is robust, and suggests some degree of correspondence between sapwood and leaf osmoregulation at the cellular level, itself potentially a function of soil potassium $\left(\mathrm{K}^{+}\right)$availability (Quesada et al., 2012), although there was not significant enough species overlap in our leaf and sapwood databases to directly assess whether $\pi_{\mathrm{o}, 1}$ tracks $\pi_{\mathrm{o}, \mathrm{x}}$. An additional possibility is that species with a tendency to osmoregulate leaf tissue also have sapwood with higher WD and embolism resistance, though recent results challenge this explanation (Binks et al., 2016). The observation that leaf $\varepsilon_{1}$ (i.e., leaf cell "stiffness") was coordinated more closely with stem WD rather than LMA (Fig. 2) may be due more to uncertainty in how $\varepsilon_{1}$ is calculated, either based on symplastic or total relative water content (RWC* or RWC, respectively) (Bartlett et al., 2012), rather than strong evidence for stem over leaf traits governing leaf cell stiffness per se. There may be a mix of both methods used in calculating $\varepsilon_{1}$ in this dataset due to ambiguity in the original publications (M. Bartlett, personal communication, 2015), so the relationship of $\varepsilon_{1}$ with WD should be viewed as tentative.

The correspondence of sapwood PV parameters and associated capacitance with WD (Fig. 3) was in some cases particularly tight $\left(r^{2}=0.84\right.$ for sapwood capacitance $\left.C_{\mathrm{ft}, \mathrm{x}}\right)$. Given the uncertainty associated with the vessel cutting artifact for which we corrected (Supplement S2), the exact relationships with WD should also be considered tentative, but the qualitative nature of WD as a first-order predictor of $C_{\mathrm{ft}, \mathrm{x}}$ should be robust. Nonetheless, the absence of data for sapwood PV traits for WD $>0.7 \mathrm{~g} \mathrm{~cm}^{-3}$ highlights a real data need, which is particularly apparent for some regions of the tropics, such as eastern and northeastern Amazonia, which have a large abundance of high wood density species (Baker et al., 2004; Quesada et al., 2012). Second-order predictors for sapwood capacitance have been identified in separate studies, which we have not explicitly dealt with here. Recently, Wolfe and Kursar (2015) identified a similar trend of $C_{\mathrm{ft}, \mathrm{x}}$ with WD, but additionally identified deciduousness as a modulator of $C_{\mathrm{ft}, \mathrm{x}}$, with evergreen species tending to have lower $C_{\mathrm{ft}, \mathrm{x}}$ at a given WD.

The increase of xylem efficiency $\left(k_{\mathrm{s}, \max , \mathrm{x}}\right)$ with $A_{\max }$ we highlighted in our synthesis (Fig. 5) has already been identified in individual studies (Brodribb et al., 2002; Santiago et 
al., 2004; Zhu et al., 2013), but to our knowledge, our study is new in demonstrating it across diverse tropical forests spanning wet, moist, and dry systems (and to some degree savanna) when incorporating WD as a secondary predictor, which increased by $13 \%$ the variance explained by $A_{\max }$ alone. This relationship underscores the functional constraint of xylem "plumbing" on leaf gas exchange. This relationship potentially presents an important constraint for plant hydraulics modeling, considering WD is a poor predictor of the relevant wood anatomical characteristics mechanistically controlling xylem hydraulic conductivity in tropical angiosperms (Poorter et al., 2010; Zanne and Falster, 2010; Zanne et al., 2010; Zieminska et al., 2015), and $A_{\max }$ serves as a powerful proxy, with WD acting as an additional constraint (albeit small) on the relevant anatomical variation. This is important in light of the relative ubiquity of leaf nitrogen and phosphorus measurements (which in turn are good proxies for $A_{\max }$; Domingues et al., 2010) relative to wood anatomical measurements (Fichtler and Worbes, 2012) in tropical forests worldwide.

Our synthesis of hydraulic traits suggests that a tradeoff between drought avoidance (as given by $C_{\mathrm{ft}, \mathrm{x}}$ ) and tolerance $\left(P_{50, \mathrm{x}}\right)$ is more prominent than between xylem efficiency $\left(k_{\mathrm{s}, \max , \mathrm{x}}\right)$ and safety $\left(P_{50, \mathrm{x}}\right)$, though more data are needed to corroborate the limited data suggesting the former (Fig. 5). Partially responsible for this weak safety-efficiency trade-off is methodological variation in terms of how $k_{\mathrm{s}, \max , \mathrm{x}}$ is measured (Gleason et al., 2016). However, there is undoubtedly a real component to this weak trade-off, as intervessel pit membrane thickness, which does not necessarily correlate with hydraulic conductivity, is a strong anatomical predictor of $P_{50, x}$ (Li et al., 2016). Perhaps of greater significance, however, is understanding patterns associated with the presence or absence of the safety-efficiency tradeoff in particular bioclimatic regions. The correspondence of this trade-off with tropical dry forests where stem economic traits closely track leaf economic traits (Markesteijn et al., 2011a, b; Mendez-Alonzo et al., 2012), in contrast to their wetter counterparts (Baraloto et al., 2010), suggests that the hydraulic safety-efficiency trade-off may be an underlying mechanism for the extent to which stem and leaf trait coupling is observed.

\subsection{Model limitations}

Our analysis reveals some limitations of our particular approach to trait-driven plant hydraulics modeling, namely that not all trait-trait relationships are of sufficient predictive accuracy to enable simulations with low uncertainty (most notably leaf drought tolerance traits and the leaf: sapwood area ratio; see Figs. 2 and 6). This is a likely outcome of the reality that emergent properties of biological systems arise from the combination of multiple traits and their associated tradeoffs; thus, no single trait is likely to explain the majority of an emergent process (Mencuccini et al., 2015). More work identifying general plant trait-hydraulic trait relationships is justified, but should consider incorporation of multiple traits for improved realism and accuracy, and should emphasize understanding how trees as an integrated system function.

One consequence of using the empirical trait-trait correlations given here is to either under- or overestimate the range of any given hydraulic trait in a simulated community of individuals, depending on the hydraulic trait of interest. For example, in our model experiment in which we varied a single trait (Fig. 10), variation in xylem-specific hydraulic conductivity $\left(k_{\mathrm{s}, \max , \mathrm{x}} ;\right.$ Fig. $\left.10 \mathrm{c}, \mathrm{d}\right)$, which was derived from the full range of observed $\mathrm{P}_{\mathrm{L}}$ (and, hence, modeled $A_{\max }$ ) at this site, was limited to only $1.1-2.9 \mathrm{~kg} \mathrm{~m}^{-1} \mathrm{MPa}^{-1} \mathrm{~s}^{-1}$, which is only $\sim 15 \%$ of the range of observed $k_{\mathrm{s}, \max , \mathrm{x}}$ values for tropical moist forests (cf. green points, Fig. S3). Indeed it seems unlikely that the observed range of $k_{\mathrm{s}, \max , \mathrm{x}}$ at this site would be this small. On the other hand, the range of $A_{1}: A_{\mathrm{s}}$ predicted by LMA and tree height (Fig. 6 and $7 \mathrm{~g}$ ) is likely overestimated; we found that individuals with $A_{1}: A_{\mathrm{S}}$ greater than the maximum observed $A_{1}: A_{\mathrm{S}}\left(1.8 \mathrm{~m}^{2} \mathrm{~cm}^{-2}\right)$ for whole trees in the Calvo-Alvarado et al. (2008) study were unviable (whole-tree conductance was insufficient for any appreciable tree transpiration to occur). Indeed, our result showing that a slight negative bias results when all individuals receive distinct trait values according to the community trait distribution vs. a single community-mean value (Fig. 13a vs. 13b) follows as a consequence. Furthermore, in contrast to our simple implementation of hydraulic architecture, $A_{1}: A_{\mathrm{s}}$ may vary substantially throughout a tree's crown, at different branching levels, or different light environments (see Schuldt et al., 2011, as an example), given the deviations from selfsimilar, volume-filling branching and area-preserving $A_{\mathrm{s}}$ that have been observed (Whitehead et al., 1984; Bentley et al., 2013; Smith et al., 2014).

\subsection{Practical implications}

Because TFS v.1-Hydro parameterized the majority of tree hydraulic traits at the scale of plant tissues and built the sizescaling into the model (rather than specifying hydraulic properties at the whole-tree level), it has great potential for being used as a tool in data assimilation and other inverse approaches when in situ field data on sap flow, water potential, or water content data are available at one or multiple points within individual trees. This may aid in deciphering unobserved or unobservable processes, such as diagnosing where within the soil-plant continuum hydraulic limitation or embolism may be occurring (branches, stems, or fine roots) or how much stored water is used for daily transpiration.

A second benefit to its method of construction is that the constitutive equations of the model (i.e., the relationships between water potential and water content, and between hydraulic conductivity and water potential) use formulations from plant physiology (such as PV theory) and, as a consequence, have parameters (Table 2 ) that are empirically mea- 
surable and biologically interpretable. Hence, as more of these hydraulics data become available, this model can readily incorporate this information by either substituting the empirical trait relationships with measured quantities or updating the empirical hydraulic trait relationships.

Finally, the "fraction of maximum stomatal conductance" $\left(\mathrm{FMC}_{\mathrm{gs}}\right)$ encapsulates the hydraulic limitation of each tree and is implemented in a similar fashion to traditional soilbased "beta" approaches (Powell et al., 2013). While this approach might seem simplistic relative to the comparative rigor of the hydraulics scheme, we note that (1) the present function (Eq. 8) is based on leaf water potential, a new prognostic, non-steady-state metric of tree water status that integrates individual-level differences in hydraulic traits, size, and microenvironment (e.g., light) in addition to soil water potential; (2) there is no consensus as to the exact mechanism (direct or indirect) by which stomata respond to leaf water potential - recent theoretical developments on stomatal function are largely restricted to the effects of temperature and humidity alone (Buckley, 2005; Peak and Mott, 2011; Nikinmaa et al., 2013); and (3) this approach simplifies the interface between the hydraulics module and the host model.

\subsection{Future directions}

In light of the limitations to our empirical approach for parameterizing hydraulic traits via more commonly measured traits, one potential alternative for parameterizing community-level hydraulic trait variation is to do so independent of other traits employed by the model. One approach is to use the Taylor and Thompson (1986) resampling algorithm to resample individuals or species with values in multiple trait databases, which were used in this paper, but sparse database overlap may limit the utility of this approach. Alternatively, region-specific distributions of individual hydraulic traits from the databases presented here could be coupled with empirical relationships among hydraulic traits as given by our synthesis of coordination and trade-offs among hydraulic traits (Fig. 8). This analysis suggested that two independent hydraulic trait spectra may be sufficient: one safetyefficiency or avoidance-tolerance trait spectrum and potentially a stomatal hydraulic safety spectrum. More work is needed to clarify these hydraulic coordination and trade-off surfaces and, in particular, to quantify how much residual variation is real or due to measurement biases.

From an empirical perspective, explaining the remaining 16-95\% of unexplained variance in hydraulic traits shown here should be of high priority. We suggest some additional traits that show promise. The volumetric fractions of airspace, water, and solid material in leaves and stems (sensu Roderick et al., 1999; Roderick and Berry, 2001) are one such trait. For leaves, these volumetric fractions have been shown to explain much more variance in leaf PV traits than LMA and WD (Sack et al., 2003; Bouche et al., 2015; Buckley, 2015; Scoffoni, 2015). While not as routine of a mea- surement in comparison to LMA, these measurements are not as intensive as the full PV curve. Second, identifying the strongest wood anatomical correlates of xylem vulnerability to embolism $\left(P_{50, \mathrm{x}}\right)$ should also be of high priority, such as the thickness of the intervessel pit membranes (Choat et al., 2008; Jansen et al., 2009), as well as improving understanding of the air-seeding mechanism (Schenk et al., 2015; Jansen and Schenk, 2015) Third, and perhaps most important for whole-tree hydraulics, is more data on hydraulic architecture. Tuning hydraulic architecture in our dynamic model proved to be a key "knob" for matching observations. Additional measurements of $A_{1}: A_{\mathrm{s}}$, xylem taper, and crown-branching patterns should not be conducted in isolation, rather in tandem with each other and with other leaf and stem economic traits (in particular LMA, as suggested by Fig. 6b) to isolate physical constraints on structure and the dynamics of whole-tree transpiration (Smith et al., 2014). The paired relationship of $A_{1}: A_{\mathrm{S}}$ with xylem taper as integrative measures of whole-tree hydraulic regulation is virtually nonexistent for tropical forests, although collocated measurements of these two traits exist (Zach et al., 2010; Horna et al., 2011).

For modeling hydraulic impacts on stomatal closure, we favored the use of a "stomatal vulnerability function", but this is one possibility among many. Specifically, multiple studies have found that branch $\psi$ rarely falls below that at which stem capacitance begins to decrease precipitously (Meinzer et al., 2008b; Wolfe and Kursar, 2015), and stomatal regulation has also been observed to track leaf turgor loss points (Brodribb et al., 2003). Whether stomatal closure in response to water stress in tropical forests forms an entirely distinct "safety margin" axis (Martinez-Vilalta et al., 2014; Skelton et al., 2015) or maps on to other hydraulic traits remains to be elucidated. A recent review highlights the interacting roles of both hydraulic supply and vapor pressure deficit in controlling stomatal responses, which we have not yet accounted for (Sperry and Love, 2015). We also did not include into our model variability in leaf-level hydraulic conductance, or comparative values for root traits. While terminal branches and leaves account for a majority of total plant resistance due in part to xylem taper, roots may be more vulnerable to embolism for the same reason and therefore represent a weak link in drought-induced mortality; these should be topics of future work.

\section{Conclusions}

We present a plant hydraulics model based on biologically interpretable and measurable plant hydraulic traits and rooted in established plant physiology theory. It is capable of scaling tissue-level hydraulic traits to whole-tree hydraulic function. Embedding it within an individual tree trait-driven model allowed us to explore how individual-level variation in hydraulic traits (including tree size) interacts with light envi- 
ronments to drive differences in hydraulic function across individuals. Addition of plant hydraulics made substantial improvements to modeled transpiration fluxes during periods of high incoming radiation. Our synthesis of data for the tropics on a wide range of hydraulic traits needed to parameterize the model allowed us to develop empirical relationships among commonly measured plant traits and less common hydraulic traits. These empirical relationships are analogous to pedotransfer functions (Clapp and Hornberger, 1978; Cosby et al., 1984) developed for predicting soil hydraulic properties as a function of soil textural "traits". While they should be refined as more data become available, they are an important first step towards representing ecological dimensions of hydraulic trait variation in process ecosystem models. Critically, this individual- and trait-driven framework provides a test bed for identifying both critical processes and functional traits needed for inclusion in coarse-scale Earth system models (ESMs). Likely some degree of simplification of the present approach will be required upon implementation in ESMs; nonetheless we expect that inclusion of trait-driven plant hydraulics schemes will lead to reduced uncertainty in the future state of tropical forests under climate change.

\section{Code availability}

The JAVA source code for TFS v.1-Hydro can be obtained from the corresponding author upon request.

\section{Data availability}

The Supplement S4 describes supplementary data for this paper. Leaf PV data (Figs. 2 and 8) that were newly extracted from publications are available as .csv data files as described under the heading "Leaf PV database". Leaf PV data originating from pre-existing leaf PV databases are available by accessing the original articles cited under the heading "Leaf PV database". Sapwood PV data (Figs. 3, S2.1, and S2.3) are available as .csv data files as described under the heading "Sapwood PV database". Sapwood area data (Fig. 7h) are available as .csv data files as described under the heading "Sapwood Area database". Xylem hydraulic trait data (Figs. 4, 5, 8, and S2.2) that were newly extracted from publications are available as .csv data files as described under the heading "Xylem Functional Traits Database". Xylem hydraulic trait data originating from the TRY archive can be accessed from this archive (http://www.try-db.org); the references of data from that archive used in analyses here are given under the heading "Xylem Functional Traits Database". Sapwood area and sapwood PV databases are given in Christoffersen (2016a) and Christoffersen (2016b), respectively.

\author{
The Supplement related to this article is available online \\ at doi:10.5194/gmd-9-4227-2016-supplement.
}

Acknowledgements. This research was supported in part by the European Union Seventh Framework Programme, under the project AMAZALERT (grant agreement no. 282664 to Patrick Meir supporting Bradley O. Christoffersen; overall grant led by Bart Kruijt, and also supporting Manuel Gloor, Sophie Fauset, David R. Galbraith, and Timothy R. Baker) and by the Next-Generation Ecosystem Experiments (NGEE-Tropics) project, funded by the U.S. Department of Energy, Office of Biological and Environmental Research (supporting Bradley O. Christoffersen, Chonggang $\mathrm{Xu}$, and Nate G. McDowell). The Los Alamos National Laboratory LDRD program also partially supported Chonggang Xu, Bradley O. Christoffersen, and Sanna Sevanto. Sanna Sevanto was also partially supported by The Los Alamos Survival-Mortality Experiment (SUMO) funded by the U.S. DOE, Office of Science, BER. The UK NERC grant NE/J011002/1 partially supported Patrick Meir and Maurizio Mencuccini. Patrick Meir also acknowledges ARC support from FT110100457. Sophie Fauset was supported by the NERC grants "ECOFOR" (grant ref: NE/K01644X/1) and "AMAZONICA" (NE/F005806/1). This submission is under public release with the approved LA-UR-16-20338. We thank all colleagues who contributed data to the Xylem Functional Traits Database, as well as Rick Meinzer for sharing ancillary LMA data and Megan Bartlett for answering clarifying questions. We additionally thank Brett Wolfe, Rafael Oliveira, Yadvinder Malhi, Ethan Coon, Dan Johnson, and John Sperry for helpful discussions, and Mark Decker and Guo-Yue Niu for helpful discussions regarding the use of the mass-based solution to the Richards equation. We are grateful for the constructive criticisms of two anonymous referees, which improved the overall clarity of this manuscript.

Edited by: H. Sato

Reviewed by: two anonymous referees

\section{References}

Alton, P., Fisher, R., Los, S., and Williams, M.: Simulations of global evapotranspiration using semiempirical and mechanistic schemes of plant hydrology, Global Biogeochem. Cy., 23, GB4023, doi:10.1029/2009GB003540, 2009.

Anderegg, W. R. L.: Spatial and temporal variation in plant hydraulic traits and their relevance for climate change impacts on vegetation, New Phytol., 205, 1008-1014, 2015.

Arbogast, T., Obeyesekere, M., and Wheeler, M.: Numerical Methods for the Simulation of Flow in Root-Soil Systems, SIAM J. Numer. Anal., 30, 1677-1702, 1993.

Baker, T. R., Phillips, O. L., Malhi, Y., Almeida, S., Arroyo, L., Di Fiore, A., Erwin, T., Killeen, T., Laurance, S., Laurance, W. F., Lewis, S. L., Lloyd, J., Monteagudo, A., Neill, D., Patino, S., Pitman, N. C. A., Silva, J. N. M., and Vasquez Martinez, R.: Variation in wood density determines spatial patterns in Amazonian forest biomass, Glob. Change Biol., 10, 545-562, 2004. 
Baltzer, J. L., Davies, S. J., Bunyavejchewin, S., and Noor, N. S. M.: The role of desiccation tolerance in determining tree species distributions along the Malay-Thai Peninsula, Funct. Ecol., 22, 221-231, 2008.

Baraloto, C., Timothy Paine, C. E., Poorter, L., Beauchene, J., Bonal, D., Domenach, A.-M., Hérault, B., Patiño, S., Roggy, J.C., and Chave, J.: Decoupled leaf and stem economics in rain forest trees, Ecol. Lett., 13, 1338-1347, 2010.

Bartlett, M. K., Scoffoni, C., and Sack, L.: The determinants of leaf turgor loss point and prediction of drought tolerance of species and biomes: a global meta-analysis, Ecol. Lett., 15, 393-405, 2012.

Bennett, A. C., McDowell, N. G., Allen, C. D., and AndersonTeixeira, K. J.: Larger trees suffer most during drought in forests worldwide, Nat. Plants, 1, 15139, doi:10.1038/nplants.2015.139, 2015.

Bentley, L. P., Stegen, J. C., Savage, V. M., Smith, D. D., von Allmen, E. I., Sperry, J. S., Reich, P. B., and Enquist, B. J.: An empirical assessment of tree branching networks and implications for plant allometric scaling models, Ecol. Lett., 16, 1069-1078, 2013.

Binks, O., Meir, P., Rowland, L., da Costa, A. C. L., Vasconcelos, S. S., de Oliveira, A. A. R., Ferreira, L., Christoffersen, B., Nardini, A., and Mencuccini, M.: Plasticity in leaf-level water relations of tropical rainforest trees in response to experimental drought, New Phytol., 211, 477-488, 2016.

Bohlman, S. and Pacala, S.: A forest structure model that determines crown layers and partitions growth and mortality rates for landscape-scale applications of tropical forests, J. Ecol., 100, 508-518, 2012.

Bohrer, G., Mourad, H., Laursen, T. A., Drewry, D., Avissar, R., Poggi, D., Oren, R., and Katul, G. G.: Finite element tree crown hydrodynamics model $(\mathrm{FETCH})$ using porous media flow within branching elements: A new representation of tree hydrodynamics, Water Resour. Res., 41, W11404, doi:10.1029/2005WR004181, 2005.

Boisier, J. P., Ciais, P., Ducharne, A., and Guimberteau, M.: Projected strengthening of Amazonian dry season by constrained climate model simulations, Nature Clim. Change, 5, 656-660, 2015.

Bonan, G. B., Williams, M., Fisher, R. A., and Oleson, K. W.: Modeling stomatal conductance in the earth system: linking leaf water-use efficiency and water transport along the soilplant-atmosphere continuum, Geosci. Model Dev., 7, 21932222, doi:10.5194/gmd-7-2193-2014, 2014.

Borchert, R.: Soil and Stem Water Storage Determine Phenology and Distribution of Tropical Dry Forest Trees, Ecology, 75, 1437-1449, 1994.

Bouche, P. S., Delzon, S., Choat, B., Badel, E., Brodribb, T. J., Burlett, R., Cochard, H., Charra-Vaskou, K., Lavigne, B., Li, S., Mayr, S., Morris, H., Torres Ruiz, J. M., Zufferey, V., and Jansen, S.: Are needles of Pinus pinaster more vulnerable to xylem embolism than branches? New insights from Xray computed tomography, Plant Cell Environ., 39, 860-870, doi:10.1111/pce.12680, 2015.

Brodribb, T. J., Holbrook, N. M., and Gutierrez, M. V.: Hydraulic and photosynthetic co-ordination in seasonally dry tropical forest trees, Plant Cell Environ., 25, 1435-1444, 2002.
Brodribb, T. J., Holbrook, N. M., Edwards, E. J., and Gutierrez, M. V.: Relations between stomatal closure, leaf turgor and xylem vulnerability in eight tropical dry forest trees, Plant Cell Environ., 26, 443-450, 2003.

Brodribb, T. J., Skelton, R. P., McAdam, S. A. M., Bienaimé, D., Lucani, C. J., and Marmottant, P.: Visual quantification of embolism reveals leaf vulnerability to hydraulic failure, New Phytol., 209, 1403-1409, 2016.

Buckley, T. N.: The control of stomata by water balance, New Phytol., 168, 275-292, 2005.

Buckley, T. N.: The contributions of apoplastic, symplastic and gas phase pathways for water transport outside the bundle sheath in leaves, Plant Cell Environ., 38, 7-22, 2015.

Cai, W., Borlace, S., Lengaigne, M., van Rensch, P., Collins, M., Vecchi, G., Timmermann, A., Santoso, A., McPhaden, M. J., Wu, L., England, M. H., Wang, G., Guilyardi, E., and Jin, F.-F.: Increasing frequency of extreme El Nino events due to greenhouse warming, Nature Clim. Change, 4, 111-116, 2014.

Calvo-Alvarado, J. C., McDowell, N. G., and Waring, R. H.: Allometric relationships predicting foliar biomass and leaf area:sapwood area ratio from tree height in five Costa Rican rain forest species, Tree Physiol., 28, 1601-1608, 2008.

Carswell, F. E.: Seasonality in $\mathrm{CO}_{2}$ and $\mathrm{H}_{2} \mathrm{O}$ flux at an eastern Amazonian rain forest, J. Geophys. Res., 107, 8076, doi:10.1029/2000JD000284, 2002.

Chapotin, S. M., Razanameharizaka, J. H., and Holbrook, N. M.: Water relations of baobab trees (Adansonia spp. L.) during the rainy season: does stem water buffer daily water deficits?, Plant Cell Environ., 29, 1021-1032, 2006.

Chave, J., Coomes, D., Jansen, S., Lewis, S. L., Swenson, N. G., and Zanne, A. E.: Towards a worldwide wood economics spectrum, Ecol. Lett., 12, 351-366, 2009.

Choat, B., Sack, L., and Holbrook, N. M.: Diversity of hydraulic traits in nine Cordia species growing in tropical forests with contrasting precipitation, New Phytol., 175, 686-698, 2007.

Choat, B., Cobb, A. R., and Jansen, S.: Structure and function of bordered pits: new discoveries and impacts on whole-plant hydraulic function, New Phytol., 177, 608-626, 2008.

Choat, B., Drayton, W. M., Brodersen, C., Matthews, M. A., Shackel, K. A., Wada, H., and McElrone, A. J.: Measurement of vulnerability to water stress-induced cavitation in grapevine: a comparison of four techniques applied to a long-vesseled species, Plant Cell Environ., 33, 1502-1512, 2010.

Choat, B., Jansen, S., Brodribb, T. J., Cochard, H., Delzon, S., Bhaskar, R., Bucci, S. J., Feild, T. S., Gleason, S. M., Hacke, U. G., Jacobsen, A. L., Lens, F., Maherali, H., Martínez-Vilalta, J., Mayr, S., Mencuccini, M., Mitchell, P. J., Nardini, A., Pittermann, J., Pratt, R. B., Sperry, J. S., Westoby, M., Wright, I. J., and Zanne, A. E.: Global convergence in the vulnerability of forests to drought, Nature, 491, 752-755, doi:10.1038/nature11688, 2012.

Christoffersen, B.: Pantropical Tree Sapwood Area Data, 1977-2015, NGEE Tropics Data Collection, doi:10.15486/NGT/1256473, 2016a.

Christoffersen, B.: Pantropical Tree Sapwood Hydraulic Properties, 1991-2014, NGEE Tropics Data Collection, doi:10.15486/NGT/1256474, 2016b.

Christoffersen, B. O., Restrepo-Coupe, N., Arain, M. A., Baker, I. T., Cestaro, B. P., Ciais, P., Fisher, J. B., Galbraith, D., Guan, 
X., Gulden, L., van den Hurk, B., Ichii, K., Imbuzeiro, H., Jain, A., Levine, N., Miguez-Macho, G., Poulter, B., Roberti, D. R., Sakaguchi, K., Sahoo, A., Schaefer, K., Shi, M., Verbeeck, H., Yang, Z.-L., Araújo, A. C., Kruijt, B., Manzi, A. O., da Rocha, H. R., von Randow, C., Muza, M. N., Borak, J., Costa, M. H., Gonçalves de Gonçalves, L. G., Zeng, X., and Saleska, S. R.: Mechanisms of water supply and vegetation demand govern the seasonality and magnitude of evapotranspiration in Amazonia and Cerrado, Agr. Forest Meteorol., 191, 33-50, 2014.

Clapp, R. B. and Hornberger, G. M.: Empirical equations for some soil hydraulic properties, Water Resour. Res., 14, 601-604, 1978.

Cochard, H., Herbette, S., Barigah, T., Badel, E., Ennajeh, M., and Vilagrosa, A.: Does sample length influence the shape of xylem embolism vulnerability curves? A test with the Cavitron spinning technique, Plant Cell Environ., 33, 1543-1552, 2010.

Condit, R., Engelbrecht, B. M. J., Pino, D., Pérez, R., and Turner, B. L.: Species distributions in response to individual soil nutrients and seasonal drought across a community of tropical trees, $\mathrm{P}$. Natl. Acad. Sci., 110, 5064-5068, 2013.

Corner, E. J. H.: The Durian Theory or the Origin of the Modern Tree, Ann. Bot.-London, 13, 367-414, 1949.

Cosby, B. J., Hornberger, G. M., Clapp, R. B., and Ginn, T. R.: A statistical exploration of the relationships of soil moisture characteristics to the physical properties of soils, Water Resour. Res., 20, 682-690, 1984.

da Costa, A. C. L., Galbraith, D., Almeida, S., Portela, B. T. T., da Costa, M., de Athaydes Silva Junior, J., Braga, A. P., de Gonçalves, P. H. L., de Oliveira, A. A. R., Fisher, R., Phillips, O. L., Metcalfe, D. B., Levy, P., and Meir, P.: Effect of 7 yr of experimental drought on vegetation dynamics and biomass storage of an eastern Amazonian rainforest, New Phytol., 187, 579-591, 2010.

Darcy, H.: Les fontaines publiques de la ville de Dijon: exposition et application, Victor Dalmont, Paris, France, 1856.

da Rocha, H. R., Manzi, A. O., Cabral, O. M., Miller, S. D., Goulden, M. L., Saleska, S. R., Coupe, N. R., Wofsy, S. C., Borma, L. S., Artaxo, P., Vourlitis, G., Nogueira, J. S., Cardoso, F. L., Nobre, A. D., Kruijt, B., Freitas, H. C., von Randow, C., Aguiar, R. G., and Maia, J. F.: Patterns of water and heat flux across a biome gradient from tropical forest to savanna in Brazil, J. Geophys. Res.-Biogeo., 114, G00B12, doi:10.1029/2007JG000640, 2009.

Ding, Y., Zhang, Y., Zheng, Q.-S., and Tyree, M. T.: Pressurevolume curves: revisiting the impact of negative turgor during cell collapse by literature review and simulations of cell micromechanics, New Phytol., 203, 378-387, 2014.

Domec, J.-C., Ogée, J., Noormets, A., Jouangy, J., Gavazzi, M., Treasure, E., Sun, G., McNulty, S. G., and King, J. S.: Interactive effects of nocturnal transpiration and climate change on the root hydraulic redistribution and carbon and water budgets of southern United States pine plantations, Tree Physiol., 32, 707-723, 2012.

Domingues, T. F., Meir, P., Feldpausch, T. R., Saiz, G., Veenendaal, E. M., Schrodt, F., Bird, M., Djagbletey, G., Hien, F., Compaore, H., Diallo, A., Grace, J., and Lloyd, J.: Co-limitation of photosynthetic capacity by nitrogen and phosphorus in West Africa woodlands, Plant Cell Environ., 33, 959-980, 2010.

Duursma, R. A. and Medlyn, B. E.: MAESPA: a model to study interactions between water limitation, environmental drivers and vegetation function at tree and stand levels, with an example application to $\left[\mathrm{CO}_{2}\right] \times$ drought interactions, Geosci. Model Dev., 5, 919-940, doi:10.5194/gmd-5-919-2012, 2012.

Edwards, W. R. N., Jarvis, P. G., Landsberg, J. J., and Talbot, H.: A dynamic model for studying flow of water in single trees, Tree Physiol., 1, 309-324, 1986.

Egea, G., Verhoef, A., and Vidale, P. L.: Towards an improved and more flexible representation of water stress in coupled photosynthesis-stomatal conductance models, Agr. Forest Meteorol., 151, 1370-1384, 2011.

Engelbrecht, B. J. and Kursar, T.: Comparative drought-resistance of seedlings of 28 species of co-occurring tropical woody plants, Oecologia, 136, 383-393, 2003.

Engelbrecht, B. M. J., Comita, L. S., Condit, R., Kursar, T. A., Tyree, M. T., Turner, B. L., and Hubbell, S. P.: Drought sensitivity shapes species distribution patterns in tropical forests, Nature, 447, 80-82, 2007.

Enquist, B. J. and Enquist, C. A. F.: Long-term change within a Neotropical forest: assessing differential functional and floristic responses to disturbance and drought, Glob. Change Biol., 17, 1408-1424, 2011.

Fauset, S., Baker, T. R., Lewis, S. L., Feldpausch, T. R., AffumBaffoe, K., Foli, E. G., Hamer, K. C., Swaine, M. D., and Etienne, R.: Drought-induced shifts in the floristic and functional composition of tropical forests in Ghana, Ecol. Lett., 15, 1120 1129, 2012.

Feddes, R. A., Kowalik, P. J., and Zaradny, H.: Simulation of Field Water Use and Crop Yield, John Wiley, New York, USA, 1978.

Feng, X., Porporato, A., and Rodriguez-Iturbe, I.: Changes in rainfall seasonality in the tropics, Nature Clim. Change, 3, 811-815, 2013.

Fichtler, E. and Worbes, M.: Wood anatomical variables in tropical trees and their relation to site conditions and individual tree morphology, IAWA J., 33, 119-140, 2012.

Fisher, R. A., Williams, M., Do Vale, R. L., Da Costa, A. L., and Meir, P.: Evidence from Amazonian forests is consistent with isohydric control of leaf water potential, Plant Cell Environ., 29, 151-165, 2006.

Fisher, R. A., Williams, M., da Costa, A. L., Malhi, Y., da Costa, R. F., Almeida, S., and Meir, P.: The response of an Eastern Amazonian rain forest to drought stress: results and modelling analyses from a throughfall exclusion experiment, Glob. Change Biol., 13, 2361-2378, 2007.

Fisher, R. A., Muszala, S., Verteinstein, M., Lawrence, P., Xu, C., McDowell, N. G., Knox, R. G., Koven, C., Holm, J., Rogers, B. M., Spessa, A., Lawrence, D., and Bonan, G.: Taking off the training wheels: the properties of a dynamic vegetation model without climate envelopes, CLM4.5(ED), Geosci. Model Dev., 8, 3593-3619, doi:10.5194/gmd-8-3593-2015, 2015.

Fu, R., Yin, L., Li, W., Arias, P. A., Dickinson, R. E., Huang, L., Chakraborty, S., Fernandes, K., Liebmann, B., Fisher, R., and Myneni, R. B.: Increased dry-season length over southern Amazonia in recent decades and its implication for future climate projection, P. Natl. Acad. Sci., 110, 18110-18115, 2013.

Fyllas, N. M., Patiño, S., Baker, T. R., Bielefeld Nardoto, G., Martinelli, L. A., Quesada, C. A., Paiva, R., Schwarz, M., Horna, V., Mercado, L. M., Santos, A., Arroyo, L., Jiménez, E. M., Luizão, F. J., Neill, D. A., Silva, N., Prieto, A., Rudas, A., Silviera, M., Vieira, I. C. G., Lopez-Gonzalez, G., Malhi, Y., Phillips, O. L., 
and Lloyd, J.: Basin-wide variations in foliar properties of Amazonian forest: phylogeny, soils and climate, Biogeosciences, 6 , 2677-2708, doi:10.5194/bg-6-2677-2009, 2009.

Fyllas, N. M., Gloor, E., Mercado, L. M., Sitch, S., Quesada, C. A., Domingues, T. F., Galbraith, D. R., Torre-Lezama, A., Vilanova, E., Ramírez-Angulo, H., Higuchi, N., Neill, D. A., Silveira, M., Ferreira, L., Aymard C., G. A., Malhi, Y., Phillips, O. L., and Lloyd, J.: Analysing Amazonian forest productivity using a new individual and trait-based model (TFS v.1), Geosci. Model Dev., 7, 1251-1269, doi:10.5194/gmd-7-1251-2014, 2014.

Galbraith, D., Levy, P. E., Sitch, S., Huntingford, C., Cox, P., Williams, M., and Meir, P.: Multiple mechanisms of Amazonian forest biomass losses in three dynamic global vegetation models under climate change, New Phytol., 187, 647-665, 2010.

Gash, J. H. C. and Nobre, C. A.: Climatic effects of Amazonian deforestation: Some results from ABRACOS, B. Am. Meteorol. Soc., 78, 823-830, 1997.

Gleason, S. M., Westoby, M., Jansen, S., Choat, B., Hacke, U. G., Pratt, R. B., Bhaskar, R., Brodribb, T. J., Bucci, S. J., Cao, K.F., Cochard, H., Delzon, S., Domec, J.-C., Fan, Z.-X., Feild, T. S., Jacobsen, A. L., Johnson, D. M., Lens, F., Maherali, H., Martínez-Vilalta, J., Mayr, S., McCulloh, K. A., Mencuccini, M., Mitchell, P. J., Morris, H., Nardini, A., Pittermann, J., Plavcová, L., Schreiber, S. G., Sperry, J. S., Wright, I. J., and Zanne, A. E.: Weak tradeoff between xylem safety and xylem-specific hydraulic efficiency across the world's woody plant species, New Phytol., 209, 123-136, 2016.

Gloor, M., Brienen, R. J. W., Galbraith, D., Feldpausch, T. R., Schöngart, J., Guyot, J. L., Espinoza, J. C., Lloyd, J., and Phillips, O. L.: Intensification of the Amazon hydrological cycle over the last two decades, Geophys. Res. Lett., 40, 1729-1733, 2013.

Hallé, F., Oldeman, R., and Tomlinson, P.: Tropical Trees and Forests: An Architectural Analysis, Springer-Verlag, New York, USA, 441, 1978.

Hasler, N. and Avissar, R.: What controls evapotranspiration in the amazon basin?, J. Hydrometeorol., 8, 380-395, 2007.

Hickler, T., Prentice, I. C., Smith, B., Sykes, M. T., and Zaehle, S.: Implementing plant hydraulic architecture within the LPJ Dynamic Global Vegetation Model, Global Ecol. Biogeogr., 15, 567-577, doi:10.1111/j.1466-8238.2006.00254.x, 2006.

Holtta, T., Cochard, H., Nikinmaa, E., and Mencuccini, M.: Capacitive effect of cavitation in xylem conduits: results from a dynamic model, Plant Cell Environ., 32, 10-21, 2009.

Horna, V., Schuldt, B., Brix, S., and Leuschner, C.: Environment and tree size controlling stem sap flux in a perhumid tropical forest of Central Sulawesi, Indonesia, Ann. For. Sci., 68, 10271038, 2011.

Jansen, S. and Schenk, H. J.: On the ascent of sap in the presence of bubbles, Am. J. Bot., 102, 1561-1563, 2015.

Jansen, S., Choat, B., and Pletsers, A.: Morphological variation of intervessel pit membranes and implications to xylem function in angiosperms, Am. J. Bot., 96, 409-419, 2009.

Jansen, S., Schuldt, B., and Choat, B.: Current controversies and challenges in applying plant hydraulic techniques: International Workshop on Plant Hydraulic Techniques, Ulm University, Germany, September 2014, New Phytol., 205, 961-964, 2015.
Jarvis, P. G.: The interpretation of the variations in leaf water potential and stomatal conductance found in canopies in the field, Philos. T. Roy. Soc. B, 273, 593-610, 1976.

Jarvis, P. G., Edwards, W. R. N., and Talbot, H.: Models of plant and crop water use, in: Mathematics and Plant Physiology, edited by: Rose, E. D. and Charles-Edwards, D. A., Academic Press, London, UK, 1981.

Joetzjer, E., Douville, H., Delire, C., and Ciais, P.: Present-day and future Amazonian precipitation in global climate models: CMIP5 versus CMIP3, Clim. Dynam., 41, 2921-2936, 2013.

Joetzjer, E., Delire, C., Douville, H., Ciais, P., Decharme, B., Fisher, R., Christoffersen, B., Calvet, J. C., da Costa, A. C. L., Ferreira, L. V., and Meir, P.: Predicting the response of the Amazon rainforest to persistent drought conditions under current and future climates: a major challenge for global land surface models, Geosci. Model Dev., 7, 2933-2950, doi:10.5194/gmd-7-29332014, 2014.

Johnson, M. O., Galbraith, D., Gloor, E., De Deurwaerder, H., Guimberteau, M., Rammig, A., Thonicke, K., Verbeeck, H., von Randow, C., Monteagudo, A., Phillips, O. L., Brienen, R. J. W., Feldpausch, T. R., Lopez Gonzalez, G., Fauset, S., Quesada, C. A., Christoffersen, B., Ciais, P., Gilvan, S., Kruijt, B., Meir, P., Moorcroft, P., Zhang, K., Alvarez, E. A., Alves de Oliveira, A., Amaral, I., Andrade, A., Aragao, L. E. O. C., Araujo-Murakami, A., Arets, E. J. M. M., Arroyo, L., Aymard, G. A., Baraloto, C., Barroso, J., Bonal, D., Boot, R., Camargo, J., Chave, J., Cogollo, A., Cornejo, F. V., Costa, L. D., di Fiore, A., Ferreira, L., Higuchi, N., Honorio, E., Killeen, T. J., Laurance, S. G., Laurance, W. F., Licona, J., Lovejoy, T., Malhi, Y., Marimon, B., Marimon, B. H. J., Matos, D. C. L., Mendoza, C., Neill, D. A., Pardo, G., Peña-Claros, M., Pitman, N. C. A., Poorter, L., Prieto, A., Ramirez-Angulo, H., Roopsind, A., Rudas, A., Salomao, R. P., Silveira, M., Stropp, J., ter Steege, H., Terborgh, J., Thomas, R., Toledo, M., Torres-Lezama, A., van der Heijden, G. M. F., Vasquez, R., Vieira, I., Vilanova, E., Vos, V. A., and Baker, T. R.: Variation in stem mortality rates determines patterns of aboveground biomass in Amazonian forests: implications for dynamic global vegetation models, Glob. Change Biol., 22, 3996-4013, doi:10.1111/gcb.13315, 2016.

Klein, T.: The variability of stomatal sensitivity to leaf water potential across tree species indicates a continuum between isohydric and anisohydric behaviours, Funct. Ecol., 28, 1313-1320, 2014.

Kumagai, T. O.: Modeling water transportation and storage in sapwood - model development and validation, Agr. Forest Meteorol., 109, 105-115, 2001.

Kumagai, T. O. and Porporato, A.: Drought-induced mortality of a Bornean tropical rain forest amplified by climate change, J. Geophys. Res.-Biogeo., 117, G02032, doi:10.1029/2011JG001835, 2012.

Kursar, T. A., Engelbrecht, B. M. J., Burke, A., Tyree, M. T., Ei Omari, B., and Giraldo, J. P.: Tolerance to low leaf water status of tropical tree seedlings is related to drought performance and distribution, Funct. Ecol., 23, 93-102, 2009.

Leigh Jr., E. G.: Tropical Forest Ecology: A View from Barro Colorado Island: A View from Barro Colorado Island, Oxford University Press, New York, USA, 1999.

Lescure, J.-P., Puig, H., Riera, B., Leclerc, D., Beekman, A., and Beneteau, A.: La phytomasse épigée d'une forêt dense en Guyane française, Acta Oecol., 4, 237-251, 1983. 
Levine, N. M., Zhang, K., Longo, M., Baccini, A., Phillips, O. L., Lewis, S. L., Alvarez-Dávila, E., Segalin de Andrade, A. C., Brienen, R. J. W., Erwin, T. L., Feldpausch, T. R., Monteagudo Mendoza, A. L., Nuñez Vargas, P., Prieto, A., Silva-Espejo, J. E., Malhi, Y., and Moorcroft, P. R.: Ecosystem heterogeneity determines the ecological resilience of the Amazon to climate change, P. Natl. Acad. Sci., 113, 793-797, 2016.

Li, S., Lens, F., Espino, S., Karimi, Z., Klepsch, M., Schenk, H. J., Schmitt, M., Schuldt, B., and Jansen, S.: Intervessel pit membrane thickness as a key determinant of embolism resistance in angiosperm xylem, IAWA J., 37, 152-171, 2016.

Lopez, O. R., Kursar, T. A., Chochard, H., and Tyree, M. T.: Interspecfic variation in xylem vulnerability to cavitation among tropical tree and shurb species, Tree Physiol., 25, 1553-1562, 2005.

Mackay, D. S., Roberts, D. E., Ewers, B. E., Sperry, J. S., McDowell, N. G., and Pockman, W. T.: Interdependence of chronic hydraulic dysfunction and canopy processes can improve integrated models of tree response to drought, Water Resour. Res., 51, 6156-6176, 2015.

Manzoni, S., Vico, G., Katul, G., Palmroth, S., Jackson, R. B., and Porporato, A.: Hydraulic limits on maximum plant transpiration and the emergence of the safety-efficiency trade-off, New Phytol., 198, 169-178, 2013a.

Manzoni, S., Vico, G., Porporato, A., and Katul, G.: Biological constraints on water transport in the soil-plant-atmosphere system, Adv. Water Resour., 51, 292-304, 2013b.

Markesteijn, L., Poorter, L., Bongers, F., Paz, H., and Sack, L.: Hydraulics and life history of tropical dry forest tree species: coordination of species' drought and shade tolerance, New Phytol., 191, 480-495, 2011a.

Markesteijn, L., Poorter, L., Paz, H., Sack, L., and Bongers, F.: Ecological differentiation in xylem cavitation resistance is associated with stem and leaf structural traits, Plant Cell Environ., 34, 137148, 2011b.

Martinez-Vilalta, J., Poyatos, R., Aguade, D., Retana, J., and Mencuccini, M.: A new look at water transport regulation in plants, New Phytol., 204, 105-115, 2014.

McDowell, N. G. and Allen, C. D.: Darcy's law predicts widespread forest mortality under climate warming, Nature Clim. Change, 5, 669-672, 2015.

McDowell, N. G., Barnard, H., Bond, B. J., Hinckley, T., Hubbard, R. M., Ishii, H., Kostner, B., Magnani, F., Marshall, J. D., Meinzer, F. C., Phillips, N., Ryan, M. G., and Whitehead, D.: The relationship between tree height and leaf area: sapwood area ratio, Oecologia, 132, 12-20, 2002.

McDowell, N. G., Licata, J., and Bond, B. J.: Environmental sensitivity of gas exchange in different-sized trees, Oecologia, 145, doi:10.1007/s00442-005-0104-6, 2005.

Medlyn, B. E., Duursma, R. A., Eamus, D., Ellsworth, D. S., Prentice, I. C., Barton, C. V. M., Crous, K. Y., De Angelis, P., Freeman, M., and Wingate, L.: Reconciling the optimal and empirical approaches to modelling stomatal conductance, Glob. Change Biol., 17, 2134-2144, 2011.

Meinzer, F. C., Campanello, P. I., Domec, J. C., Gatti, M. G., Goldstein, G., Villalobos-Vega, R., and Woodruff, D. R.: Constraints on physiological function associated with branch architecture and wood density in tropical forest trees, Tree Physiol., 28, 16091617, 2008a.
Meinzer, F. C., Woodruff, D. R., Domec, J. C., Goldstein, G., Campanello, P. I., Gatti, M. G., and Villalobos-Vega, R.: Coordination of leaf and stem water transport properties in tropical forest trees, Oecologia, 156, 31-41, 2008b.

Meinzer, F. C., McCulloh, K. A., Lachenbruch, B., Woodruff, D. R., and Johnson, D. M.: The blind men and the elephant: the impact of context and scale in evaluating conflicts between plant hydraulic safety and efficiency, Oecologia, 164, 287-296, 2010.

Meir, P., Metcalfe, D. B., Costa, A. C. L., and Fisher, R. A.: The fate of assimilated carbon during drought: impacts on respiration in Amazon rainforests, Philos. T. Roy. Soc. B, 363, 1849-1855, 2008.

Meir, P., Wood, T. E., Galbraith, D. R., Brando, P. M., Da Costa, A. C. L., Rowland, L., and Ferreira, L. V.: Threshold Responses to Soil Moisture Deficit by Trees and Soil in Tropical Rain Forests: Insights from Field Experiments, Bioscience, 65, 882-892, 2015.

Mencuccini, M.: Hydraulic constraints in the functional scaling of trees, Tree Physiol., 22, 553-565, 2002.

Mencuccini, M., Hoeltttae, T., Petit, G., and Magnani, F.: Sanio's laws revisited. Size-dependent changes in the xylem architecture of trees, Ecol. Lett., 10, 1084-1093, 2007.

Mencuccini, M., Minunno, F., Salmon, Y., Martinez-Vilalta, J., and Holtta, T.: Coordination of physiological traits involved in drought-induced mortality of woody plants, New Phytol., 208, 396-409, 2015.

Mendez-Alonzo, R., Paz, H., Zuluaga, R. C., Rosell, J. A., and Olson, M. E.: Coordinated evolution of leaf and stem economics in tropical dry forest trees, Ecology, 93, 2397-2406, 2012.

Mirfenderesgi, G., Bohrer, G., Matheny, A. M., Fatichi, S., de Moraes Frasson, R. P., and Schäfer, K. V. R.: Tree level hydrodynamic approach for resolving aboveground water storage and stomatal conductance and modeling the effects of tree hydraulic strategy, J. Geophys. Res.-Biogeo., 121, 1792-1813, doi:10.1002/2016jg003467, 2016.

Moser, G., Schuldt, B., Hertel, D., Horna, V., Coners, H., Barus, H., and Leuschner, C.: Replicated throughfall exclusion experiment in an Indonesian perhumid rainforest: wood production, litter fall and fine root growth under simulated drought, Glob. Change Biol., 20, 1481-1497, 2014.

Mualem, Y.: A new model for predicting the hydraulic conductivity of unsaturated porous media, Water Resour. Res., 12, 513-522, 1976.

Myers, N., Mittermeier, R. A., Mittermeier, C. G., da Fonseca, G. A. B., and Kent, J.: Biodiversity hotspots for conservation priorities, Nature, 403, 853-858, 2000.

Nakagawa, M., Tanaka, K., Nakashizuka, T., Ohkubo, T., Kato, T., Maeda, T., Sato, K., Miguchi, H., Nagamasu, H., Ogino, K., Teo, S., Hamid, A. A., and Seng, L. H.: Impact of severe drought associated with the 1997-1998 El Nino in a tropical forest in Sarawak, J. Trop. Ecol., 16, 355-367, 2000.

Nardini, A., Luglio, J., and Thompson, K.: Leaf hydraulic capacity and drought vulnerability: possible trade-offs and correlations with climate across three major biomes, Funct. Ecol., 28, 810 818, 2014.

Nepstad, D. C., Tohver, I. M., Ray, D., Moutinho, P., and Cardinot, G.: Mortality of large trees and lianas following experimental drought in an amazon forest, Ecology, 88, 2259-2269, 2007. 
Nikinmaa, E., Hölttä, T., Hari, P., Kolari, P., Mäkelä, A., Sevanto, S., and Vesala, T.: Assimilate transport in phloem sets conditions for leaf gas exchange, Plant Cell Environ., 36, 655-669, 2013.

North, G. B. and Nobel, P. S.: Root-soil contact for the desert succulent Agave deserti in wet and drying soil, New Phytol., 135, 21-29, 1997.

Ogée, J., Brunet, Y., Loustau, D., Berbigier, P., and Delzon, S.: MuSICA, a $\mathrm{CO}_{2}$, water and energy multilayer, multileaf pine forest model: evaluation from hourly to yearly time scales and sensitivity analysis, Glob. Change Biol., 9, 697-717, 2003.

Oliveira, R. S., Dawson, T. E., Burgess, S. S. O., and Nepstad, D. C.: Hydraulic redistribution in three Amazonian trees, Oecologia, 145, 354-363, 2005.

Oliveira, R. S., Christoffersen, B. O., Barros, F. V., Teodoro, G. S., Bittencourt, P., Brum, M. M. J., and Viani, R. A. G.: Changing precipitation regimes and the water and carbon economies of trees, Theoretical and Experimental Plant Physiology, 26, 65-82, 2014.

Olson, M. E. and Rosell, J. A.: Vessel diameter-stem diameter scaling across woody angiosperms and the ecological causes of xylem vessel diameter variation, New Phytol., 197, 1204-1213, 2013.

Olson, M. E., Anfodillo, T., Rosell, J. A., Petit, G., Crivellaro, A., Isnard, S., Leon-Gomez, C., Alvarado-Cardenas, L. O., and Castorena, M.: Universal hydraulics of the flowering plants: vessel diameter scales with stem length across angiosperm lineages, habits and climates, Ecol. Lett., 17, 988-997, 2014.

Patiño, S., Fyllas, N. M., Baker, T. R., Paiva, R., Quesada, C. A., Santos, A. J. B., Schwarz, M., ter Steege, H., Phillips, O. L., and Lloyd, J.: Coordination of physiological and structural traits in Amazon forest trees, Biogeosciences, 9, 775-801, doi:10.5194/bg-9-775-2012, 2012.

Peak, D. and Mott, K. A.: A new, vapour-phase mechanism for stomatal responses to humidity and temperature, Plant Cell Environ., 34, 162-178, 2011.

Petit, G. and Anfodillo, T.: Comment on "The blind men and the elephant: the impact of context and scale in evaluating conflicts between plant hydraulic safety and efficiency" by Meinzer et al. (2010), Oecologia, 165, 271-274, discussion 275, 2011.

Phillips, O. L., Van Der Heijden, G., Lewis, S. L., López-González, G., Aragão, L. E. O. C., Lloyd, J., Malhi, Y., Monteagudo, A., Almeida, S., Dávila, E. A., Amaral, I., Andelman, S., Andrade, A., Arroyo, L., Aymard, G., Baker, T. R., Blanc, L., Bonal, D., De Oliveira, Á. C. A., Chao, K. J., Cardozo, N. D., Da Costa, L., Feldpausch, T. R., Fisher, J. B., Fyllas, N. M., Freitas, M. A., Galbraith, D., Gloor, E., Higuchi, N., Honorio, E., Jiménez, E., Keeling, H., Killeen, T. J., Lovett, J. C., Meir, P., Mendoza, C., Morel, A., Vargas, P. N., Patiño, S., Peh, K. S. H., Cruz, A. P., Prieto, A., Quesada, C. A., Ramírez, F., Ramírez, H., Rudas, A., Salamão, R., Schwarz, M., Silva, J., Silveira, M., Ferry Slik, J. W., Sonké, B., Thomas, A. S., Stropp, J., Taplin, J. R. D., Vásquez, R., and Vilanova, E.: Drought-mortality relationships for tropical forests, New Phytol., 187, 631-646, 2010.

Poorter, L., McDonald, I., Alarcón, A., Fichtler, E., Licona, J.-C., Peña-Claros, M., Sterck, F., Villegas, Z., and Sass-Klaassen, U.: The importance of wood traits and hydraulic conductance for the performance and life history strategies of 42 rainforest tree species, New Phytol., 185, 481-492, 2010.
Powell, T. L., Galbraith, D. R., Christoffersen, B. O., Harper, A., Imbuzeiro, H. M. A., Rowland, L., Almeida, S., Brando, P. M., da Costa, A. C. L., Costa, M. H., Levine, N. M., Malhi, Y., Saleska, S. R., Sotta, E., Williams, M., Meir, P., and Moorcroft, P. R.: Confronting model predictions of carbon fluxes with measurements of Amazon forests subjected to experimental drought, New Phytol., 200, 350-365, doi:10.1111/nph.12390, 2013.

Purves, D. W., Lichstein, J. W., and Pacala, S. W.: Crown plasticity and competition for canopy space: a new spatially implicit model parameterized for 250 North American tree species, PLoS One, 2, e870, doi:10.1371/journal.pone.0000870, 2007.

Quesada, C. A., Phillips, O. L., Schwarz, M., Czimczik, C. I., Baker, T. R., Patiño, S., Fyllas, N. M., Hodnett, M. G., Herrera, R., Almeida, S., Alvarez Dávila, E., Arneth, A., Arroyo, L., Chao, K. J., Dezzeo, N., Erwin, T., di Fiore, A., Higuchi, N., Honorio Coronado, E., Jimenez, E. M., Killeen, T., Lezama, A. T., Lloyd, G., López-González, G., Luizão, F. J., Malhi, Y., Monteagudo, A., Neill, D. A., Núñez Vargas, P., Paiva, R., Peacock, J., Peñuela, M. C., Peña Cruz, A., Pitman, N., Priante Filho, N., Prieto, A., Ramírez, H., Rudas, A., Salomão, R., Santos, A. J. B., Schmerler, J., Silva, N., Silveira, M., Vásquez, R., Vieira, I., Terborgh, J., and Lloyd, J.: Basin-wide variations in Amazon forest structure and function are mediated by both soils and climate, Biogeosciences, 9, 2203-2246, doi:10.5194/bg-9-2203-2012, 2012.

R Core Team: R: a language and environment for statistical computing, R Foundation for Statistical Computing, Vienna, Austria, 2015.

Reich, P. B.: The world-wide "fast-slow" plant economics spectrum: a traits manifesto, J. Ecol., 102, 275-301, 2014.

Roderick, M. L. and Berry, S. L.: Linking wood density with tree growth and environment: a theoretical analysis based on the motion of water, New Phytol., 149, 473-485, 2001.

Roderick, M. L., Berry, S. L., Noble, I. R., and Farquhar, G. D.: A theoretical approach to linking the composition and morphology with the function of leaves, Funct. Ecol., 13, 683-695, 1999.

Rohatgi, A.: WebPlotDigitizer, available at: http://arohatgi.info/ WebPlotDigitizer, last access: 15 May 2016.

Rowland, L., da Costa, A. C., Galbraith, D. R., Oliveira, R. S., Binks, O. J., Oliveira, A. A., Pullen, A. M., Doughty, C. E., Metcalfe, D. B., Vasconcelos, S. S., Ferreira, L. V., Malhi, Y., Grace, J., Mencuccini, M., and Meir, P.: Death from drought in tropical forests is triggered by hydraulics not carbon starvation, Nature, 528, 119-122, 2015a.

Rowland, L., Harper, A., Christoffersen, B. O., Galbraith, D. R., Imbuzeiro, H. M. A., Powell, T. L., Doughty, C., Levine, N. M., Malhi, Y., Saleska, S. R., Moorcroft, P. R., Meir, P., and Williams, M.: Modelling climate change responses in tropical forests: similar productivity estimates across five models, but different mechanisms and responses, Geosci. Model Dev., 8, 10971110, doi:10.5194/gmd-8-1097-2015, 2015b.

Rowland, L., Lobo-do-Vale, R. L., Christoffersen, B. O., Melém, E. A., Kruijt, B., Vasconcelos, S. S., Domingues, T., Binks, O. J., Oliveira, A. A. R., Metcalfe, D., da Costa, A. C. L., Mencuccini, M., and Meir, P.: After more than a decade of soil moisture deficit, tropical rainforest trees maintain photosynthetic capacity, despite increased leaf respiration, Glob. Change Biol., 21, 46624672, doi:10.1111/gcb.13035, 2015c.

Sack, L. and Pasquet-Kok, J.: Leaf pressure-volume curve parameters, available at: http://prometheuswiki.publish.csiro.au/ 
tiki-citation.php?page=Leafpressure-volumecurveparameters (last access: 15 February 2015), 2011.

Sack, L., Cowan, P. D., Jaikumar, N., and Holbrook, N. M.: The "hydrology" of leaves: co-ordination of structure and function in temperate woody species, Plant Cell Environ., 26, 1343-1356, 2003.

Sakschewski, B., von Bloh, W., Boit, A., Rammig, A., Kattge, J., Poorter, L., Penuelas, J., and Thonicke, K.: Leaf and stem economics spectra drive diversity of functional plant traits in a dynamic global vegetation model, Glob. Change Biol., 21, 27112725, doi:10.1111/gcb.12870, 2015.

Sakschewski, B., von Bloh, W., Boit, A., Poorter, L., Pena-Claros, M., Heinke, J., Joshi, J., and Thonicke, K.: Resilience of Amazon forests emerges from plant trait diversity, Nature Clim. Change, 6, 1032-1036, doi:10.1038/nclimate3109, 2016.

Santiago, L. S., Goldstein, G., Meinzer, F. C., Fisher, J. B., Machado, K., Woodruff, D., and Jones, T.: Leaf photosynthetic traits scale with hydraulic conductivity and wood density in Panamanian forest canopy trees, Oecologia, 140, 543-550, 2004.

Savage, V. M., Bentley, L. P., Enquist, B. J., Sperry, J. S., Smith, D. D., Reich, P. B., and von Allmen, E. I.: Hydraulic trade-offs and space filling enable better predictions of vascular structure and function in plants, P. Natl. Acad. Sci., 107, 22722-22727, 2010.

Schenk, H. J., Steppe, K., and Jansen, S.: Nanobubbles: a new paradigm for air-seeding in xylem, Trends Plant Sci., 20, 199205, 2015

Scholz, F. G., Bucci, S. J., Goldstein, G., Meinzer, F. C., Franco, A. C., and Miralles-Wilhelm, F.: Biophysical properties and functional significance of stem water storage tissues in Neotropical savanna trees, Plant Cell Environ., 30, 236-248, 2007.

Schuldt, B., Leuschner, C., Horna, V., Moser, G., Köhler, M., van Straaten, O., and Barus, H.: Change in hydraulic properties and leaf traits in a tall rainforest tree species subjected to long-term throughfall exclusion in the perhumid tropics, Biogeosciences, 8 , 2179-2194, doi:10.5194/bg-8-2179-2011, 2011.

Scoffoni, C.: Modelling the outside-xylem hydraulic conductance: towards a new understanding of leaf water relations, Plant Cell Environ., 38, 4-6, 2015.

Sheffield, J., Goteti, G., and Wood, E. F.: Development of a 50-year high-resolution global dataset of meteorological forcings for land surface modeling, J. Climate, 19, 3088-3111, 2006.

Siau, J. F.: Transport processes in wood, Springer Verlag, Berlin, Germany, 1984.

Silva Dias, M. A. F., Rutledge, S., Kabat, P., Silva Dias, P. L., Nobre, C., Fisch, G., Dolman, A. J., Zipser, E., Garstang, M., Manzi, A. O., Fuentes, J. D., Rocha, H. R., Marengo, J., Plana-Fattori, A., Sá, L. D. A., Alvalá, R. C. S., Andreae, M. O., Artaxo, P., Gielow, R., and Gatti, L.: Cloud and rain processes in a biosphere-atmosphere interaction context in the Amazon Region, J. Geophys. Res.-Atmos., 107, 8072, doi:10.1029/2001JD000335, 2002.

Siqueira, M., Katul, G., and Porporato, A.: Onset of water stress, hysteresis in plant conductance, and hydraulic lift: Scaling soil water dynamics from millimeters to meters, Water Resour. Res., 44, W01432, doi:10.1029/2007WR006094, 2008.

Skelton, R. P., West, A. G., and Dawson, T. E.: Predicting plant vulnerability to drought in biodiverse regions using functional traits, P. Natl. Acad. Sci. USA, 112, 5744-5749, 2015.
Smith, D. D., Sperry, J. S., Enquist, B. J., Savage, V. M., McCulloh, K. A., and Bentley, L. P.: Deviation from symmetrically selfsimilar branching in trees predicts altered hydraulics, mechanics, light interception and metabolic scaling, New Phytol., 201, 217229, 2014.

Solomon, S.: Climate change 2007 - the physical science basis: Working group I contribution to the fourth assessment report of the IPCC, Cambridge University Press, Cambridge, UK and New York, NY, USA, 2007.

Sperry, J. S. and Love, D. M.: What plant hydraulics can tell us about responses to climate-change droughts, New Phytol., 207, 14-27, 2015.

Sperry, J. S., Adler, F. R., Campbell, G. S., and Comstock, J. P.: Limitation of plant water use by rhizosphere and xylem conductance: results from a model, Plant Cell Environ., 21, 347-359, 1998.

Sperry, J. S., Meinzer, F. C., and McCulloh, K. A.: Safety and efficiency conflicts in hydraulic architecture: scaling from tissues to trees, Plant Cell Environ., 31, 632-645, 2008.

Sperry, J. S., Christman, M. A., Torres-Ruiz, J. M., Taneda, H., and Smith, D. D.: Vulnerability curves by centrifugation: is there an open vessel artefact, and are " $r$ " shaped curves necessarily invalid?, Plant Cell Environ., 35, 601-610, 2012.

Stark, S. C., Leitold, V., Wu, J. L., Hunter, M. O., de Castilho, C. V., Costa, F. R. C., McMahon, S. M., Parker, G. G., Shimabukuro, M. T., Lefsky, M. A., Keller, M., Alves, L. F., Schietti, J., Shimabukuro, Y. E., Brandão, D. O., Woodcock, T. K., Higuchi, N., de Camargo, P. B., de Oliveira, R. C., and Saleska, S. R.: Amazon forest carbon dynamics predicted by profiles of canopy leaf area and light environment, Ecol. Lett., 15, 1406-1414, 2012.

Stewart, G. R., Gracia, C. A., Hegarty, E. E., and Specht, R. L.: Reductase Activity and Chlorophyll Content in Sun Leaves of Subtropical Australian Closed-Forest (Rainforest) and Open-Forest Communities, Oecologia, 82, 544-551, 1990.

Strigul, N., Pristinski, D., Purves, D., Dushoff, J., and Pacala, S.: Scaling from trees to forests: tractable macroscopic equations for forest dynamics, Ecol. Monogr., 78, 523-545, 2008.

Taylor, M. S. and Thompson, J. R.: A data based algorithm for the generation of random vectors, Comput. Stat. Data An., 4, 93101, 1986.

ter Steege, H., Pitman, N. C. A., Sabatier, D., Baraloto, C., Salomão, R. P., Guevara, J. E., Phillips, O. L., Castilho, C. V., Magnusson, W. E., Molino, J.-F., Monteagudo, A., Núñez Vargas, P., Montero, J. C., Feldpausch, T. R., Coronado, E. N. H., Killeen, T. J., Mostacedo, B., Vasquez, R., Assis, R. L., Terborgh, J., Wittmann, F., Andrade, A., Laurance, W. F., Laurance, S. G. W., Marimon, B. S., Marimon, B.-H., Guimarães Vieira, I. C., Amaral, I. L., Brienen, R., Castellanos, H., Cárdenas López, D., Duivenvoorden, J. F., Mogollón, H. F., Matos, F. D. d. A. and Dávila, N., García-Villacorta, R., Stevenson Diaz, P. R., Costa, F., Emilio, T., Levis, C., Schietti, J., Souza, P., Alonso, A., Dallmeier, F. and Montoya, A. J. D., Fernandez Piedade, M. T., Araujo-Murakami, A., Arroyo, L., Gribel, R., Fine, P. V. A., Peres, C. A., Toledo, M., Aymard C, G. A., Baker, T. R., Cerón, C., Engel, J., Henkel, T. W., Maas, P., Petronelli, P., Stropp, J., Zartman, C. E., Daly, D., Neill, D., Silveira, M., Paredes, M. R., Chave, J., Lima Filho, D. d. A., Jørgensen, P. M., Fuentes, A., Schöngart, J., Cornejo Valverde, F., Di Fiore, A., Jimenez, E. M., Peñuela Mora, M. 
C., Phillips, J. F., Rivas, G., van Andel, T. R., von Hildebrand, P., Hoffman, B., Zent, E. L., Malhi, Y., Prieto, A., Rudas, A. and Ruschell, A. R., Silva, N., Vos, V., Zent, S., Oliveira, A. A., Schutz, A. C., Gonzales, T., Trindade Nascimento, M., RamirezAngulo, H., Sierra, R. and Tirado, M., Umaña Medina, M. N., van der Heijden, G., Vela, C. I. A. and Vilanova Torre, E., Vriesendorp, C., Wang, O., Young, K. R., Baider, C. and Balslev, H., Ferreira, C., Mesones, I., Torres-Lezama, A., Urrego Giraldo, L. E., Zagt, R., Alexiades, M. N., Hernandez, L., HuamantupaChuquimaco, I., Milliken, W., Palacios Cuenca, W., Pauletto, D. and Valderrama Sandoval, E., Valenzuela Gamarra, L., Dexter, K. G., Feeley, K., Lopez-Gonzalez, G., and Silman, M. R.: Hyperdominance in the Amazonian Tree Flora, Science, 342, 6156, doi:10.1126/science.1243092, 2013.

Tobin, M. F., Lopez, O. R., and Kursar, T. A.: Responses of Tropical Understory Plants to a Severe Drought: Tolerance and Avoidance of Water Stress, Biotropica, 31, 570-578, 1999.

Tomasella, J. and Hodnett, M. G.: Marked differences between van Genuchten soil water-retention parameters for temperate and tropical soils: a new water-retention pedo-transfer functions developed for tropical soils, Geoderma, 108, 155-180, 2002.

Tyree, M. T. and Hammel, H. T.: Measurement of Turgor Pressure and Water Relations of Plants by Pressure-Bomb Technique, J. Exp. Bot., 23, 267-282, doi:10.1093/jxb/23.1.267, 1972.

Tyree, M. T. and Yang, S.: Water-storage capacity of Thuja, Tsuga, and Acer stems measured by dehyration isotherms: The contribution of capillary water and cavitation, Planta, 182, 420-426, 1990.

Tyree, M. T., Snyderman, D. A., Wilmot, T. R., and Machado, J.L.: Water relations and hydraulic architecture of a tropical tree (Schefflera morototoni), Plant Physiol., 96, 1105-1113, 1991.

van der Sande, M. T., Arets, E. J. M. M., Peña-Claros, M., de Avila, A. L., Roopsind, A., Mazzei, L., Ascarrunz, N., Finegan, B., Alarcón, A., Cáceres-Siani, Y., Licona, J. C., Ruschel, A., Toledo, M., and Poorter, L.: Old-growth Neotropical forests are shifting in species and trait composition, Ecol. Monogr., 86, 228 243, 2016.

van Genuchten, M. T.: A closed-form equation for predicting the hydraulic conductivity of unsaturated soils, Soil Sci. Soc. Am. J., 44, 892-898, 1980.

Verhoef, A. and Egea, G.: Modeling plant transpiration under limited soil water: Comparison of different plant and soil hydraulic parameterizations and preliminary implications for their use in land surface models, Agr. Forest Meteorol., 191, 22-32, 2014.

Wang, R., Zhang, L., Zhang, S., Cai, J., and Tyree, M. T.: Water relations of Robinia pseudoacacia L.: do vessels cavitate and refill diurnally or are R-shaped curves invalid in Robinia?, Plant Cell Environ., 37, 2667-2678, 2014.

West, G. B., Brown, J. H., and Enquist, B. J.: A general model for the structure and allometry of plant vascular systems, Nature, 400, 664-667, 1999.

Whitehead, D., Edwards, W. R. N., and Jarvis, P. G.: Conducting sapwood area, foliage area, and permeability in mature trees of Picea sitchensis and Pinus contorta, Can. J. Forest Res., 14, 940947, 1984

Williams, M., Rastetter, E. B., Fernandes, D. N., Goulden, M. L., Wofsy, S. C., Shaver, G. R., Melillo, J. M., Munger, J. W., Fan, S. M., and Nadelhoffer, K. J.: Modelling the soil-plant-atmosphere continuum in a Quercus-Acer stand at Harvard forest: The reg- ulation of stomatal conductance by light, nitrogen and soil/plant hydraulic properties, Plant Cell Environ., 19, 911-927, 1996.

Williams, M., Malhi, Y., Nobre, A. D., Rastetter, E. B., Grace, J., and Pereira, M. G. P.: Seasonal variation in net carbon exchange and evapotranspiration in a Brazilian rain forest: a modelling analysis, Plant Cell Environ., 21, 953-968, 1998.

Williams, M., Bond, B. J., and Ryan, M. G.: Evaluating different soil and plant hydraulic constraints on tree function using a model and sap flow data from ponderosa pine, Plant Cell Environ., 24, 679-690, 2001.

Wolfe, B. and Kursar, T.: Diverse patterns of stored water use among saplings in seasonally dry tropical forests, Oecologia, 179, 925-936, doi:10.1007/s00442-015-3329-z, 2015.

Wright, I. J., Reich, P. B., Westoby, M., Ackerly, D. D., Baruch, Z., Bongers, F., Cavender-Bares, J., Chapin, T., Cornelissen, J. H. C., Diemer, M., Flexas, J., Garnier, E., Groom, P. K., Gulias, J., Hikosaka, K., Lamont, B. B., Lee, T., Lee, W., Lusk, C., Midgley, J. J., Navas, M.-L., Niinemets, U., Oleksyn, J., Osada, N., Poorter, H., Poot, P., Prior, L., Pyankov, V. I., Roumet, C., Thomas, S. C., Tjoelker, M. G., Veneklaas, E. J., and Villar, R.: The worldwide leaf economics spectrum, Nature, 428, 821-827, 2004.

Xu, C., McDowell, N. G., Sevanto, S., and Fisher, R. A.: Our limited ability to predict vegetation dynamics under water stress, New Phytol., 200, 298-300, 2013.

Xu, X., Medvigy, D., Powers, J. S., Becknell, J. M., and Guan, K.: Diversity in plant hydraulic traits explains seasonal and interannual variations of vegetation dynamics in seasonally dry tropical forests, New Phytol., 212, 80-95, doi:10.1111/nph.14009, 2016.

Zach, A., Schuldt, B., Brix, S., Horna, V., Culmsee, H., and Leuschner, C.: Vessel diameter and xylem hydraulic conductivity increase with tree height in tropical rainforest trees in $\mathrm{Su}-$ lawesi, Indonesia, Flora - Morphology, Distribution, Funct. Ecol of Plants, 205, 506-512, 2010.

Zanne, A. E. and Falster, D. S.: Plant functional traits - linkages among stem anatomy, plant performance and life history, New Phytol., 185, 348-351, 2010.

Zanne, A. E., Lopez-Gonzalez, G., Coomes, D. A., Ilic, J., Jansen, S., Lewis, S. L., Miller, R. B., Swenson, N. G., Wiemann, M. C., and Chave, J.: Data from: Towards a worldwide wood economics spectrum, Dryad Digital Repository, doi:10.5061/dryad.234, 2009.

Zanne, A. E., Westoby, M., Falster, D. S., Ackerly, D. D., Loarie, S. R., Arnold, S. E. J., and Coomes, D. A.: Angiosperm wood structure: Global patterns in vessel anatomy and their relation to wood density and potential conductivity, Am. J. Bot., 97, 207215, 2010.

Zhu, S. D., Song, J. J., Li, R. H., and Ye, Q.: Plant hydraulics and photosynthesis of 34 woody species from different successional stages of subtropical forests, Plant Cell Environ, 36, 879-891, 2013.

Zieminska, K., Westoby, M., and Wright, I. J.: Broad Anatomical Variation within a Narrow Wood Density Range - A Study of Twig Wood across 69 Australian Angiosperms, PLoS One, 10, e0124892, doi:10.1371/journal.pone.0124892, 2015. 